$\checkmark$ Research Square

\title{
Revisiting mechanisms of the Mesoamerican Midsummer drought
}

Jorge Luis García-Franco ( $\nabla$ jorge.garcia-franco@physics.ox.ac.uk)

Oxford University: University of Oxford https://orcid.org/0000-0002-0396-9744

\section{Robin Chadwick}

Met Office

Lesley Gray

University of Oxford

Scott Osprey

University of Oxford

David K Adams

Universidad Nacional Autonoma de Mexico

\section{Research Article}

Keywords: precipitation, Mexico, Central America, CMIP6, cloud-radiative effect, bimodal seasonal cycle

Posted Date: February 24th, 2022

DOI: https://doi.org/10.21203/rs.3.rs-1351433/v1

License: (c) (i) This work is licensed under a Creative Commons Attribution 4.0 International License.

Read Full License 
1. Revisiting mechanisms of the Mesoamerican Midsummer drought radiative mechanisms.

Observations show that the seasonal cycle of precipitation in parts of southern Mexico and Central America exhibits a bimodal signal, known as the Midsummer drought (MSD), but there is no consensus on which processes are most relevant for the two-peak structure of the rainy season. This paper evaluates three hypotheses that could explain the MSD: the SST cloud-radiative feedback, the solar declination angle and the Caribbean LowLevel Jet (CLLJ) moisture transport hypotheses. Model experiments produced by the Met Office Hadley Centre (MOHC) for CMIP6 as well as ERA5 reanalysis data are used to critically assess the predictions of each hypothesis. The simulations capture the double peak signal of precipitation well and reasonably simulate the spatial and temporal variations of the MSD and other relevant climate features such as the CLLJ. Evidence from our analysis suggests that the Eastern Pacific SSTs do not increase in late summer in ERA5 data and only slightly increase in the simulations. More importantly, the Eastern Pacific SST variability in ERA5 and in the model experiments cannot explain the differences in the seasonality of precipitation. The net shortwave radiation at the surface shows a two-peak seasonal cycle; however, this behaviour appears to result from a strong anti-correlation of the incoming shortwave and convective activity due to cloud radiative-effects. There was no evidence found by this study of a causal link in which absorption of shortwave energy forces precipitation variations, as suggested by the solar declination angle hypothesis. The moisture convergence, CLLJ and the precipitable water vapor variations best explain the characteristics of the observed and simulated MSD, particularly for the onset of the MSD. The diagnosed variations of moisture convergence, which are synchronous with the timing of the MSD, point to a dynamic mechanism in which the low-level inflow from the Caribbean is more important for the MSD than other

Keywords: precipitation, Mexico, Central America, CMIP6, cloud-radiative effect, 


\section{Introduction}

bimodal seasonal cycle

The annual cycle of precipitation in parts of southern Mexico, Central America and the Caribbean exhibits a bimodal signal characterized by two wetter periods and a drier period in between during Midsummer, most commonly referred to as Midsummer drought (MSD; Mosiño and García, 1966, Magaña et al., 1999, Gamble et al., 2008, PerdigónMorales et al., 2018, Zhao and Zhang, 2021) or locally as canícula and Veranillo (Dilley, 1996). The MSD, as a relatively drier spell during the rainy season, is known to impact agriculture and crop-yield (Jobbová et al., 2018, Harvey et al., 2018), and recent evidence has highlighted both changes to the timing of the MSD (Anderson et al., 2019) and increasingly damaging impacts of droughts to local farmers (Hellin et al., 2017, Chen et al., 2017). The relevance of the MSD calls for improved seasonal and climate predictions of its strength and timing. However, our understanding of the physical mechanisms that cause the MSD is still very limited.

Since the early analyses of the characteristics of the MSD, research has aimed to understand the physical mechanisms that cause this peculiar two-peak structure of precipitation (e.g. Hastenrath, 1967, Magaña et al., 1999, Giannini et al., 2000, Curtis, 2002, Herrera et al., 2015, Hidalgo et al., 2015, Maldonado et al., 2016, Zermeño-Díaz, 2019). For instance, Hastenrath (1967) first suggested that a double-crossing of the east Pacific Intertropical Convergence Zone (ITCZ) can explain the MSD, so the first peak of precipitation is associated with the early summer northward crossing of the ITCZ and the second peak with the southward displacement of the ITCZ during late summer. This theory, however, fails to explain the MSD signal seen in northeastern Mexico (e.g., in the state of Tamaulipas) at latitudes of $29^{\circ} \mathrm{N}$ (Perdigón-Morales et al., 2018, Zhao and Zhang, 2021, García-Franco et al., 2021).

Several hypotheses now exist to explain the timing and strength of the MSD in Mesoamerica (e.g. Angeles et al., 2010, Hidalgo et al., 2015, Maldonado et al., 2016, Perdigón-Morales et al., 2019), yet, to date, there is no comprehensive accepted theory and fundamental questions remain, such as whether the MSD is caused by mechanisms that enhance precipitation either side of the MSD (Karnauskas et al., 2013) or a mechanism that inhibits rainfall at midsummer (Durán-Quesada et al., 2017), which indicates a poor understanding of the processes responsible for the MSD. Three of the leading hypotheses (illustrated in Figure 1) for the Mesoamerican MSD are: a feedback mechanism of sea-surface temperatures (SSTs) and cloud-radiative effects proposed by Magaña et al. (1999); the solar declination angle hypothesis (Karnauskas et al., 2013); and the 
Caribbean Low-Level Jet (CLLJ) as a modulator for moisture transport and convective activity (Amador et al., 2016, Durán-Quesada et al., 2017).

The SST cloud-radiative feedback mechanism (Fig. 1a) proposes that the seasonal peaks and trough in precipitation are a result of a similar seasonality in the Eastern Pacific SSTs and near-surface humidity (Magaña et al., 1999, Magaña and Caetano, 2005). During the first peak of precipitation, cloud radiative effects (CREs) block shortwave radiation from reaching the surface. The decrease in solar heating, in addition to an increase in the low-level wind flow which acts to enhance the latent heat fluxes from the ocean to the atmosphere, cool the SSTs and decrease the surface moisture available leading to a decrease in convective activity and precipitation, i.e., the MSD. During this drier period with less cloud cover, incoming shortwave increases again, weaker trade winds decrease surface fluxes and Eastern Pacific SSTs warm above $29^{\circ} \mathrm{C}$ leading to the second peak of precipitation.

The solar declination angle hypothesis (Fig. 1b) argues that the surface total shortwave radiation absorption is controlled by the bi-annual crossing of the solar declination angle (Karnauskas et al., 2013). The absorption of shortwave energy in the MSD regions force precipitation changes, according to this hypothesis, with a lag of a few days/weeks by modifying the near-surface moist static energy, specifically the surface moisture, which, in this framework, is the ultimate control on precipitation variability during the rainy season. In short, Karnauskas et al. (2013) suggest that precipitation follows the solar declination angle through the influence of the local absorption of shortwave energy on near-surface temperature and humidity so that the two peaks of precipitation are the result of one precipitation enhancing mechanism occuring twice during the rainy season.

The third mechanism proposes that the CLLJ acts as a conveyor belt and collector of moisture (Fig. 1c) and, through this role, is responsible for the double-peak signal of precipitation in the Caribbean or the MSD region (e.g. Small et al., 2007, Gamble et al., 2008, Curtis and Gamble, 2008, Herrera et al., 2015, Hidalgo et al., 2015, Martinez et al., 2019, Corrales-Suastegui et al., 2020). The main argument suggests that changes to CLLJ strength, possibly influenced by seasonal variations in the high pressure gyre in the northern subtropical Atlantic (Mapes et al., 2005), modifies moisture transport and precipitation over the Pacific coast of Central America (Muñoz et al., 2008, DuránQuesada et al., 2010, García-Martínez and Bollasina, 2020).

Dynamical mechanisms associated with the CLLJ also exist to explain the MSD of the Caribbean (e.g. Martinez et al., 2019), the frequency of eastern Pacific tropical cyclones (Fu et al., 2021), as well as decadal (Cerón et al., 2021) and intra-seasonal (Martin and Schumacher, 2011, Perdigón-Morales et al., 2019) variability of precipitation in Central 
America. The CLLJ seems to play a vital role for the regional-scale circulation and the variability of precipitation. Therefore, suggestions that the CLLJ variations are the main cause of the MSD over the Pacific coast of Mesoamerica (Herrera et al., 2015, Amador et al., 2016, Durán-Quesada et al., 2017) require further examination.

Moreover, most general circulation models (GCMs) in CMIP3/CMIP5 struggle to reasonably reproduce the MSD signal (Rauscher et al., 2008, Ryu and Hayhoe, 2014), and these biases have led other studies to use regional models or downscaled output to understand future projections of the MSD (Fuentes-Franco et al., 2015, Maurer et al., 2017, Imbach et al., 2018, Corrales-Suastegui et al., 2020, Cavazos et al., 2020). Less attention has been given as to why some CMIP models reproduce the bimodal seasonal cycle while others do not. García-Franco et al. (2020), García-Franco et al. (2021) showed that CMIP6 simulations from the Met Office Hadley Centre (MOHC) models reproduce the timing and strength of the MSD with reasonable skill, albeit with a stronger first peak and a later onset of the MSD, which motivates further use of these simulations to investigate the processes that are associated with the MSD.

There is no robust or satisfying understanding of the physical processes associated with the MSD, as illustrated by the relatively large and growing number of hypotheses to explain the timing and processes leading to this bimodal seasonal cycle. Meanwhile, more GCM (CMIP) simulations are being produced and used to predict changes to the MSD in the future without a clear sense of what processes are being well represented by the models. This lack of a comprehensive depiction of the processes of the MSD together with good representation of the spatial and temporal characteristics of the MSD in the MOHC CMIP6 experiments, are the main motivations for this paper. Specifically, this study critically assesses the three leading hypotheses for the MSD using the MOHC models and ERA5 in order to highlight the strengths and weaknesses of each hypothesis and to explain why the MOHC models are able to reproduce the bimodal signal of precipitation in the region.

The remainder of this paper is presented as follows. Section 2 describes the observational, model and reanalysis data and and the methodology to diagnose the timing of MSD. Section 3 evaluates the representation of the key features of the regional climate in the CMIP6 experiments and in ERA5. Then, the hypotheses of SST-cloud feedback (section 4), the solar declination angle (section 5) and the CLLJ (section 6) are investigated using composite and regression analysis. A summary and discussion is presented in the final section of this paper. 


\section{Data and methods}

\subsection{Observations and reanalysis data}

The precipitation datasets used are the Tropical Rainfall Measuring Mission (TRMM) version 7, product 3B42 (Huffman et al., 2010), and the Climate Hazards Infrared Precipitation with Stations (CHIRPS) (Funk et al., 2015). The remaining diagnostics are taken from ERA5 (Hersbach et al., 2020) at the $0.75^{\circ}$ resolution and for the period 19792018. Note that SSTs in ERA5 are a blended product of HadISST version 2, and OSTIA datasets (Hersbach et al., 2020). ERA5 precipitation data is used throughout this paper to compare against the models for two reasons. Firstly, observational (satellite or surface station) data of all the required diagnostics are not always available at the daily resolutions needed for this study, for example the wind flow or moisture profiles over the ocean region. Secondly, ERA5 precipitation in the MSD region closely follows the seasonal cycle of TRMM and CHIRPS, and this reanalysis reproduces well the mean timing for the MSD compared to observational datasets (García-Franco et al., 2020, García-Franco et al., 2021). Therefore, ERA5 can be compared to the simulations as another model; one that is more realistic as the reanalysis is partially driven by the observed state of the atmosphere through the radiosondes taken in the region as well as satellite data (Hersbach et al., 2020).

\subsection{CMIP6 data}

This paper uses the output from realizations of the HadGEM3 GC3.1 and from the Earth System Model UKESM1 submitted to CMIP6. These simulations use the GC3.1 configuration (Walters et al., 2019, Williams et al., 2018); the latest version of the coupled model HadGEM3 GC3.1 was run at two horizontal resolutions for CMIP6: a lowresolution configuration, labelled as N96, with an atmospheric resolution of $1.875^{\circ} \times 1.25^{\circ}$ and a $1^{\circ}$ resolution in the ocean model and a medium resolution configuration, labelled N216, with atmospheric resolution of $0.83^{\circ} \times 0.56^{\circ}$ and a $0.25^{\circ}$ oceanic resolution (Menary et al., 2018). The UKESM1 was recently developed aiming to improve the coupled model by adding processes of the Earth System (Sellar et al., 2019). These additional components include ocean biogeochemistry with coupled chemical cycles and troposphericstratospheric interactive chemistry (Mulcahy et al., 2018, Sellar et al., 2019).

This study uses the deck experiments from CMIP6: pre-industrial control, AMIP, and historical experiments from HadGEM3 GC3.1 N96 (hereafter GC31-LL) and N216 (hereafter GC31-MM), and UKESM1, which are summarised in Table 1. The pre-industrial control experiments use a constant external forcing for the year 1850, and are relatively longer integrations (Menary et al., 2018), whereas the historical experiments use our 
Table 1: Summary of the simulations used in this study detailing the experiment, CMIP activity name, acronym, model years, and number of ensemble members (Ens.).

\begin{tabular}{|c|c|c|c|c|c|}
\hline Model & Experiment & Period & Acronym & Ens. & Reference \\
\hline $\begin{array}{l}\text { HadGEM3 } \\
\text { N96 }\end{array}$ & $\begin{array}{l}\text { pre-industrial } \\
\text { control }\end{array}$ & $\begin{array}{l}1850- \\
2350\end{array}$ & CMIP/DECKGC31-LL pi & 1 & (Menary et al., 2018) \\
\hline $\begin{array}{l}\text { HadGEM3 } \\
\text { N216 }\end{array}$ & $\begin{array}{l}\text { pre-industrial } \\
\text { control }\end{array}$ & $\begin{array}{l}1850- \\
2000\end{array}$ & $\begin{array}{c}\text { CMIP/Deck } \text { GC31-MM } \\
\text { pi }\end{array}$ & 1 & (Menary et al., 2018) \\
\hline $\begin{array}{l}\text { HadGEM3 } \\
\text { N96 }\end{array}$ & historical & $\begin{array}{l}1979- \\
2014\end{array}$ & $\begin{array}{c}\text { CMIP/DECKGC31-LL } \\
\text { hist }\end{array}$ & 5 & $\begin{array}{l}\text { (Andrews et al., } \\
2020)\end{array}$ \\
\hline $\begin{array}{l}\text { HadGEM3 } \\
\text { N216 }\end{array}$ & historical & $\begin{array}{l}1979- \\
2014\end{array}$ & $\begin{array}{c}\text { CMIP/DECKGC31-MM } \\
\text { hist }\end{array}$ & 1 & (Ridley et al., 2019b) \\
\hline $\begin{array}{l}\text { HadGEM3 } \\
\text { N96 }\end{array}$ & amip & $\begin{array}{l}1979- \\
2014\end{array}$ & $\begin{array}{c}\text { CMIP/AMIPGC31-LL } \\
\text { amip }\end{array}$ & 5 & (Ridley et al., 2019a) \\
\hline $\begin{array}{l}\text { HadGEM3 } \\
\text { N216 }\end{array}$ & amip & $\begin{array}{l}1979- \\
2014\end{array}$ & $\begin{array}{c}\text { CMIP/AMIPGC31-MM } \\
\text { amip }\end{array}$ & 3 & (Ridley et al., 2019a) \\
\hline UKESM1 & $\begin{array}{l}\text { pre-industrial } \\
\text { control }\end{array}$ & $\begin{array}{l}2060- \\
2600\end{array}$ & CMIP/DECKUKESM-pi & 1 & (Tang et al., 2019b) \\
\hline UKESM1 & historical & $\begin{array}{l}1979- \\
2014\end{array}$ & CMIP/DECKKESM-hist & 6 & (Tang et al., 2019a) \\
\hline UKESM1 & amip & $\begin{array}{l}1979- \\
2014\end{array}$ & $\begin{array}{c}\text { CMIP/AMIPUKESM- } \\
\text { amip }\end{array}$ & 1 & (Tang et al., 2019a) \\
\hline
\end{tabular}


best estimate of the time-varying aerosol and greenhouse gas emissions from 1850 to 2014 (Eyring et al., 2016, Andrews et al., 2020). The AMIP experiments use the same external forcing as the historical experiments but also "nudge" the SSTs using observational products, thereby decoupling the atmosphere from the ocean and removing SST biases (Eyring et al., 2016).

Precipitation in the MOHC GC3.1 configuration is diagnosed from the large-scale and convection schemes (Walters et al., 2019). The convective scheme first diagnoses whether convection is feasible, and then whether to use the shallow or deep convection scheme. Convective precipitation is computed by the deep convection scheme which is based on the mass-flux scheme of Gregory and Rowntree (1990) modified to use a convective available potential energy (CAPE) closure and detraintment rates as a function of relative humidity (Walters et al., 2019).

\subsection{Determination of the timing of the $M S D$}

García-Franco et al. (2021) described a wavelet transform (WT) method that objectively determines the timing of the MSD in observational gridded datasets, reanalysis and climate model precipitation time series at the 5 day scale. This paper uses the WT method to determine the onset (MO) and retreat (MR) of the monsoon rainy season, as well as the onset (MSDO) and end (MSDE) of the MSD. MO and MR are determined by the maximum and minimum sum of WT coefficients computed from a dilation scale vector ranging from 24 to 54 pentads. After MO and MR are determined, a second WT is computed with dilation scales from 10 to 24 pentads and the minimum sum of the WT coefficients corresponds to the onset of the MSD and the maximum to the end of the MSD (MSDE). The timing of the first peak (P1) of precipitation is defined as the period between the MSDO and the preceding 4 pentads or 20 days, whereas the second peak (P2) is defined as the period between the date of MSDE and the subsequent 4 pentads.

An example of this separation of the MSD timing for each year is given in Figure 2, for precipitation observed from TRMM in 2017 over the study region. The area of study of this paper is southern Mexico and northwestern Central America (Fig. 3,) a region with robust MSD signals (see Perdigón-Morales et al., 2018, García-Franco et al., 2021). The WT method was applied to the TRMM, CHIRPS, ERA5 and model dataset area-averaged time-series over the study region.

\section{Climatological features}

The climatological distribution of precipitation and the temporal differences associated with MSD timing in ERA5 agree well with TRMM and CHIRPS data (Figure 
3). ERA5 captures reasonably well the climatology of precipitation over land and over the Eastern Pacific ITCZ with some positive biases (Figure S1) over the Eastern Pacific Ocean and western Mexico, and negative biases over land in southern Mexico and Central America. The patterns of the MSD-P1 and P2-MSD differences in ERA5 (Fig. 3) also agree well with TRMM. The precipitation differences associated with the MSD timing within the box in Figure $3 \mathrm{~b}$ extend well outside the study region comprising the easternmost Pacific Ocean, the entrance to the Gulf of Mexico and western Caribbean Sea, illustrating that these changes to precipitation are of regional scale.

The historical simulations (Fig. S2) show a positive bias in the EP ITCZ of 3-6 mm day $^{-1}$ as well as a dry bias over southern Mexico and Central America (García-Franco et al., 2020). The simulations capture the spatial patterns associated with the MSD stages, characterised by the highest differences found on the west coast of Mesoamerica. In agreement with observations, the precipitation differences in the MSD region in the simulations are always opposite to that of the North American monsoon region, e.g., in Figures 3 and S2 the North American monsoon regions gets wetter when the dry period begins in the MSD regions.

The seasonal cycle of precipitation in the MSD region (Fig. 4a) shows that the CMIP6 experiments and ERA5 reasonably represent the temporal distribution of rainfall (García-Franco et al., 2020). The two-peak structure of the MSD is observed in TRMM and ERA5 as two precipitation maxima (Fig. 4a), the first peak found during early to mid-June and the second peak at the end of September, separated by a drier period that spans from late June to late August. The precipitation rates in ERA5 agree well with the seasonal variation of TRMM throughout the rainy season. The MSDO pentad in the model experiments is found one or two pentads after TRMM and ERA5 and the experiments show a stronger variation in precipitation between the first peak and the MSD (García-Franco et al., 2021).

The mean rainfall observed in the three periods (P1, P2 and the MSD) in the simulations varies notably between experiments with different configurations, i.e., simulations of different horizontal resolutions, coupled ocean-atmosphere or atmosphere-only configurations, or with different external forcings (Fig. S3). The magnitude of the first and second peak precipitation rates are roughly linearly related to another but the correlation decreases between the precipitation rates during P1 and the MSD, i.e., a larger magnitude of the first peak of precipitation does not imply a wetter or drier MSD period. The magnitude of the first decrease in rainfall (MSD-P1) and the late-summer increase (P2-MSD) also show a significant spread amongst experiments which suggest that there is only a modest relationship between the magnitude of the MSD and the magnitudes of 
the two peaks of precipitation in these simulations.

The literature suggests that a number of regional features are important for precipitation variability in the MSD, including the EP SSTs, the Caribbean Sea SSTs, the EP zonal wind flow and the CLLJ (Magaña et al., 1999, Amador, 2008, Herrera et al., 2015). The comparison of the seasonal cycle of these features in ERA5 and the simulations (Fig. 4) shows that the experiments are able to replicate the seasonal variations of the SSTs and the zonal wind flow of the region reasonably well, although the seasonal cycle of the low-level winds is delayed in the experiments compared to ERA5. The EP SSTs (Fig. 4c) peak in late May, prior to the first peak of precipitation. In contrast, the Caribbean SSTs peak in early fall, about five months later, during late September. After the peak SST period in the EP, SSTs decrease to a local minimum found in July both for ERA5 and the simulations. The experiments show a cold bias in the SSTs in both regions, but this bias is most pronounced in the Caribbean Sea.

The low-level wind flow in the EP shows a bimodal seasonal cycle in all datasets (Fig. 4e). The easterly flow in the EP during the spring becomes weaker turning westerly at the end of May and reaching a local maximum in early June in ERA5 and mid-June in the simulations. This local maximum then decreases during June and early July as the zonal wind turns easterly again. The easterly flow peaks in mid-July in ERA5 and two-to-three weeks later in the model simulations. After the easterly flow peaks in the midsummer, the zonal wind becomes westerly again peaking at the end of September in both ERA5 and simulations. This seasonality of the zonal wind in the EP is similar to the seasonal cycle of precipitation in the region, with a similar delay of 2 weeks in the timing of the peaks of precipitation and zonal winds in the experiments compared to ERA5.

The CLLJ seasonal cycle (Figure 4f) is reasonably simulated by the experiments, although CLLJ peak strength, found during the last week of June in ERA5, is delayed in the simulations by about three weeks, as the simulated CLLJ peaks in mid-July in all the simulations. The simulations follow closely the CLLJ evolution in late summer and early fall, except for a notable difference in GC31-LL amip in Oct-Nov characterised by a weaker than observed CLLJ.

The outgoing long-wave radiation (OLR) and vertical velocity ( $\omega$ at $500 \mathrm{hPa}$ ) composite differences for each stage of the MSD, computed using the WT method (Fig. 5), confirm that the MSD is not a local-scale feature but the convective activity variations span a relatively wide extent of the Intra-Americas Seas. From the first peak period in the MSD, OLR and $\omega$ increase in the EP and the MSD regions and these anomalies extend into the Caribbean. Given that $\omega$ is defined as $\omega=D p / D t$ where $p$ is pressure, 
these positive anomalies are indicative of weaker ascent.

In contrast, a region several degrees west into the EP Ocean $\left(125^{\circ} \mathrm{W}\right)$ and the North American monsoon region show negative OLR and $\omega$ anomalies in the MSD-P1 panels, which suggest that simultaneously with the onset of the MSD, more active convection is observed in the North American Monsoon region (Adams and Comrie, 1997) and over the ocean west of the continent. The OLR and $\omega$ variations associated with the end of the MSD (P2-MSD) show an opposite picture to the MSD-P1 differences. Note that several of these features have been described previously by Herrera et al. (2015) and agree with previously reported "MSD patterns" (Zermeño-Díaz, 2019).

This section demonstrates that several features of the climate of the region are well represented by these models, such as the seasonality of the CLLJ and that the WT method can retrieve the so-called "MSD patterns", although some biases are apparent such as the colder SSTs throughout the region, as well as the temporal delay in the peak magnitude of the CLLJ and EP zonal winds.

\section{The SST-cloud radiative feedback}

The Eastern Pacific (EP) SSTs are a dominant factor for the variability of precipitation in the MSD region (Amador et al., 2006, Fuentes-Franco et al., 2015, Amador et al., 2016, Straffon et al., 2019) and are a key element of the SST-cloud radiative feedback mechanism proposed by Magaña et al. (1999). This mechanism predicts that EP SSTs and near-surface moisture exhibit a bimodal seasonal cycle, suggesting that the EP SSTs drive the seasonal variations in precipitation over the MSD region such that the seasonal cycle of EP SSTs and precipitation in the MSD region are very similar, but out-of-phase, with the SSTs leading precipitation. In this section, we evaluate the predictions of this hypothesis for both ERA5 and the CMIP6 experiments.

According to the feedback mechanism, the EP SSTs cool down during or just prior to the onset of the MSD and then increase during the MSD period which then enhances precipitation and causes the second peak in late summer. However, in ERA5 the EP SSTs only very slightly increase during the MSD (Jul-Aug) and cool notably in late August and September in synchrony with the second peak of increased convective activity (Fig. 4c). In the models, there is a modest second peak in EP SSTs (averaging $28.5^{\circ} \mathrm{C}$ ) in early September, nearly synchronous with the second peak of precipitation and crucially not exceeding the threshold of $29^{\circ} \mathrm{C}$ suggested by Magaña et al. (1999) as for the first peak, and the surface humidity (Fig. 4b) varies very little within the rainy season.

The WT method was used to composite SSTs and surface humidity in the P1, MSD and P2 periods. The spatial distribution of SST and surface humidity changes associated 
with the MSD (Fig. 6) suggest that the EP SSTs south of $10^{\circ} \mathrm{N}$ cool slightly between the P1 and MSD periods, meanwhile the coast of Baja California and the northern eastern Pacific warm by more than $2 \mathrm{~K}$. At the end of the MSD (P2-MSD), the EP SSTs keep cooling in both ERA5 and the simulations, instead of warming as suggested by the SST feedback mechanism. The P2-MSD panels show that the Caribbean SSTs increase, as Caribbean SSTs peak at the end of the summer (Fig. 4d). The surface humidity in the EP and MSD regions, however, is relatively unchanged (less than 0.5 $\mathrm{g} \mathrm{kg}^{-1}$ ) in ERA5 during the various stages of the MSD (Figs. 4b and 6), and in the model simulations surface humidity variations are not appreciable in the EP region, even though precipitation varies notably during these periods. Instead, the greatest variations in surface humidity are observed west of Baja California and in the North American Monsoon region.

If the EP SSTs play a dominant role in the timing and strength of the MSD, as suggested previously (Magaña et al., 1999, Magaña and Caetano, 2005, Herrera et al., 2015), then the simulations with imposed SSTs taken from observations, e.g., the GC31LL amip experiment, may be further explored to evaluate the links between SSTs and the timing or strength of the MSD. A scatter plot of the dates (pentads) of the MO, MR, MSDO and MSDE (Fig. S4) for matching years between the CHIRPS dataset and TRMM, ERA5 and the five ensemble members of GC31-LL amip shows that the timing of the MSD in GC31-LL amip are unrelated to the observed timing. This evidence suggests that the SSTs forcing the model in GC31-LL amip are not the dominant factor controlling the timing of the MSD in these atmosphere-only runs.

Alternatively, the interannual variability in ERA5 and the differences amongst the model experiments may be further explored using composite differences between the P1, MSD and P2 periods, computed for each variable for each year and then averaged to provide a mean value. These results are presented in scatter plots that aim to diagnose emergent properties and physical relationships that explain the different representations of the MSD. The mean difference in ERA5 SSTs (Fig. 7a) between the P1 and the MSD periods indicate cooling of the EP. In contrast, the coupled model simulations show a mean warming of $0.2 \mathrm{~K}$ and a greater precipitation reduction from the P1 to the MSD period. During the second peak, the EP SSTs cool (Fig. 7b) associated with a positive increase in precipitation, suggesting an inverse and weak relationship between EP SSTs and precipitation.

Furthermore, evidence shows that the surface saturation specific humidity $\mathrm{q}_{\text {sat }}$, which measures the maximum moisture that a parcel can hold, provides a strong link between local precipitation and local SSTs on seasonal time-scales over tropical oceans (Yang 
et al., 2019, Good et al., 2021). Figure 7c-d show the "remote" relationship between EP $\mathrm{q}_{\text {sat }}$ and MSD precipitation. The temporal changes to $q_{\text {sat }}$ associated with the MSD timing are negatively correlated to changes in the precipitation over the MSD region. This negative correlation also holds for the local EP $q_{\text {sat }}$-precipitation relationship (not shown) which confirms that there is no positive correlation between EP SSTs and EP or MSD precipitation.

The relationship between EP SSTs and precipitation may exist at some lag, as suggested by the radiative-convective feedback mechanism, in which the SSTs lead precipitation changes. Lag-lead correlations (Fig. 8) of the EP SSTs and the precipitation in the MSD region show that only during monsoon onset these two fields exhibit a significant positive correlation at lags of $\approx-35$ days in ERA5 and -40 to -20 days in the historical experiments.

In ERA5, the correlation for all the boreal summer (JJAS) sample is only significant for the SSTs leading precipitation region for negative lags from 30 to 40 days and is only significant (negative correlation) at positive lags at lag +5 days, indicative of an inverse SST-precipitation relationship where the SSTs follow precipitation. In the models (Fig. 8b-d), very similar results are found where significant positive correlations at negative lags, indicative of SSTs leading precipitation, are only found for the MO panel, whereas for MSDO and MSDE panels, the correlations are only significant at positive lags and for negative correlations, indicative of precipitation leading SSTs on the scale of 3-5 days and SSTs decreasing with increased precipitation.

This section investigated the SST-cloud feedback hypothesis by Magaña et al. (1999). Results in this section show that in observations, the EP SSTs do not exhibit a doublepeak seasonal cycle, so the second peak of precipitation over the MSD region cannot be driven by a second peak in EP SSTs, contradicting the SST-cloud hypothesis. Even though the simulated seasonal cycle of EP SSTs shows a bimodal signal, the second peak of EP SSTs is smaller and cannot explain the differences found between the various model experiments. Moreover, the simulations with nudged SSTs from observations (AMIP), which do not exhibit a bimodal seasonal cycle equally simulate a MSD. Finally, laglead correlations confirm that the variations of precipitation during the midsummer are not significantly correlated with variations in EP SSTs in ERA5 or in the simulations, contradicting the main arguments of this hypothesis.

\section{The solar declination angle hypothesis}

The mechanism proposed by Karnauskas et al. (2013) suggests that the amount of shortwave energy (SW) that reaches the surface is key in the driving mechanism of 
the MSD. In this hypothesis, the seasonal march of the net SW absorbed by the surface determined by the solar declination angle modulates the seasonal cycle of the near-surface temperature and humidity leading to a lagged relationship between SW and precipitation. This section evaluates the predictive capacity of this hypothesis that the local absorption of SW in the MSD region modulates the variability of precipitation throughout the rainy season.

According to Karnauskas et al. (2013), the net SW (the difference between upwelling and downwelling shortwave fluxes) at the surface should have a bimodal seasonal cycle just as precipitation. In both ERA5 and the simulations, the seasonal cycle of the net SW (Fig. 9a) exhibits a bimodal signal characterized by a first local maximum in late May, followed by a local minimum during June and a secondary increase in Jul-Aug coinciding with the MSD. After this second local maximum, there is another sharp decrease of net SW in late summer. This behaviour closely follows the seasonal cycle of precipitation (but with the opposite sign).

The patterns of changes to the net SW at the surface through the MSD stages (Fig. 10) show that from the first peak to the MSD there is a positive difference in net SW, indicative of more SW energy absorption at the surface, of approximately $30 \mathrm{~W} \mathrm{~m}^{-2}$ in ERA5 and $40 \mathrm{~W} \mathrm{~m}^{-2}$ in the simulations. The P2-MSD differences reveal a notable reduction in net SW energy throughout the North American continent. One might reasonably then suspect that the increased SW absorption during the MSD period may be part of the mechanism for the second peak of precipitation, as suggested by Karnauskas et al. (2013). On the other hand, this correlation could be highlighting the coupling between clouds, radiation and precipitation and not necessarily evidence that SW heating is the actual driving mechanism.

These hypotheses are further tested through scatter plots and lag-lead regression analysis (Fig. 11). The scatter plots show that the interannual variability of net SW in ERA5 is negatively correlated to the interannual variability of precipitation. Similarly, in simulations, the reduction in SW in the MSD-P1 shows a strong and negative correlation with the changes in precipitation. The amount of SW absorbed in the MSD is also negatively correlated with the precipitation increase during the second peak (P2-MSD). In other words, years in which less shortwave is absorbed in the MSD have stronger second peaks in the MSD region, in disagreement with solar declination angle hypothesis.

Lag-lead correlations (Fig. 11c, d) confirm that there is a strong negative correlation between SW and precipitation at lag 0 . This negative correlation illustrates that strong precipitation periods are associated with less shortwave absorbed by the surface, resulting from CREs blocking effects of incoming SW. Correlations are not significant outside of lag 
-5 to 5 days near the MSDE date, or around the MSDO date (not shown), although they appear significant for some coupled simulations at lags of -40 days when the entire JJA season is considered. These results contradict the argument of Karnauskas et al. (2013) which suggested a lagged relationship between shortwave absoprtion at the surface and precipitation throughout the various stages of the MSD.

Cloud-radiative effects (CREs) are coupled to the tropical circulation (Bony et al., 2004, Webb et al., 2017), influence the timing and strength of monsoons and column radiative heating (Guo et al., 2015, Byrne and Zanna, 2020), and modulate the amount of SW that reaches the surface (Allan, 2011). To investigate the role of CREs over the net $\mathrm{SW}$, the surface cloud radiative effect $\left(\mathrm{CRE}_{\text {surf }}\right)$ is computed from daily-mean fields following Allan (2011), as the sum of the longwave (LW) and SW CREs, i.e.:

$$
\begin{aligned}
C R E_{\text {surf }} & =L W C R E_{\text {surf }}+S W C R E_{\text {surf }} \\
& =L D S-L U S-\left(L D S_{c s}-L U S_{c s}\right)+S D S-S U S-\left(S D S_{c s}-S U S_{c s}\right),
\end{aligned}
$$

where the fluxes are depicted as long-wave (L) or short-wave (S) and downwelling (D) or upwelling (U) at the surface $(\mathrm{S})$ and the suscript ${ }_{c s}$ denotes under clear-sky conditions. The long-wave upwelling at the surface (LUS) cancels with the LUS $_{c s}$ because the longwave emission from the surface does not dependent on the presence of clouds (Allan, 2011). The net CRE at the surface is then given by:

$$
C R E_{\text {surf }}=L D S-L D S_{c s}+S D S-S U S-S D S_{c s}+S U S_{c s} .
$$

The $\mathrm{CRE}_{\text {surf }}$ during $\mathrm{P} 1, \mathrm{MSD}$ and $\mathrm{P} 2$ periods (Fig. S5) is negative and the minimum values are found in the EP ITCZ region. The minimum CRE in the EP and the Mesoamerican region is found during the two peaks of precipitation with weaker CREs during the MSD (Fig. S6). The comparison of the individual contributions of the SW and LW surface CREs show that the dominant term in the EP and Mesoamerican regions is the SW term (Figs. 9 and S7), as the LW term (Fig. S8) is generally smaller in magnitude than the SW term, especially over the EP ITCZ region. The seasonal cycle of the SW, LW and net CREs (Fig. 9b-d) show bimodal signals characterized by stronger CREs during the two peak periods during June and September and a relative minimum during the MSD.

This section shows that there is strong negative correlation between SW absorbed by the surface and precipitation, and there is no evidence for a positive correlation at any lag, as suggested by the solar declination angle hypothesis. Evidence suggests that 
CREs are likely the reason for the anticorrelation between precipitation and the net SW throughout the rainy season.

\section{The role of the Caribbean Low-Level Jet}

Several roles have been attributed to the CLLJ to explain a link between the low-level wind flow over the Caribbean Sea and the MSD in southern Mexico and Central America (see e.g. Gamble et al., 2008, Herrera et al., 2015, Zermeño-Díaz, 2019, Corrales-Suastegui et al., 2020). The main dynamical argument that links the MSD and the CLLJ is centred around variations in moisture flux convergence (MFC), and would subsequently influence the mass content of water vapor or total water content (TWC) (see e.g. Herrera et al., 2015, Durán-Quesada et al., 2017). Section 3 shows that the seasonal cycle of the CLLJ is relatively well represented by the model simulations (see Fig. 4f), but the timing of the peak magnitude of the CLLJ in the simulations is delayed by about three weeks with respect to ERA5. The timing of the start of the MSD is also notably delayed in the simulations by around 10 days, according to García-Franco et al. (2021) which suggests that the CLLJ may be playing a role in the timing of the MSD in the simulations, which aligns well with the CLLJ hypothesis.

The CLLJ strength is measured in this study through the $850 \mathrm{hPa}$ zonal wind in the Caribbean Sea (see box in Figure 3) for both model and reanalysis data. Additionally, we use the integrated moisture flux convergence (IMFC) and precipitable water vapor or TWC in the MSD region to explore this hypothesis. The IMFC was calculated using the following equation from daily data from ERA5 and the simulations:

$$
I M F C=-\langle\nabla \cdot \vec{u} q\rangle,
$$

where $q$ is the specific humidity at each pressure level, $\vec{u}$ is the wind vector and $\nabla$ is the horizontal divergence operator and the \langle\rangle operator denotes column integrals in the troposphere.

The seasonal cycles of the IMFC and TWC (Fig. 12) averaged over the region of the MSD show a strong bimodal signal, with two maxima in IMFC and TWC occurring roughly at the same time as the two peaks in precipitation in June and September and a minimum found during July to August. The simulations closely follow the timing of the variations of the seasonal cycle of ERA5, but with an overall weaker IMFC and less TWC throughout the rainy season.

The patterns of the IMFC, TWC and 850-hPa zonal wind variations associated with the MSD (MSD-P1 and P2-MSD) are shown in Figure 13. The patterns observed in the 
low-level wind vectors associated with the MSD timing are similar to the "MSD patterns" described previously Zermeño-Díaz (2019), Zhao et al. (2020), which confirms that the WT method is able to skilfully diagnose variations in the low-level wind associated with the MSD. The wind flow pattern in the MSD-P1 panel is characterised, both in ERA5 and the simulations, by northeasterly anomalies in the Gulf of Mexico and the CSEA and strong easterly anomalies over the EP region, which indicate that the wind field changes from a weak low-level westerly wind to an easterly wind at lower levels 950-700 $\mathrm{hPa}$ (see also Fig. 4e). At the end of the MSD, the wind direction changes again to a westerly direction in the EP, whereas the wind anomalies in the CSEA turn to westerlies indicative of a weakening of the CLLJ, coinciding with the second peak of precipitation observed in the MSD region.

The IMFC and TWC show coherent variations with the timing of the seasonal cycle of precipitation in the MSD region, with less moisture convergence and TWC during the drier period compared to the two peak periods. Simultaneous with this drying in southern Mexico and Central America during the MSD, the North American monsoon region moistens (increased TWC and IMFC). In the P2-MSD panel, positive differences in the MSD region and negative anomalies southward of the MSD in the EP region suggest increased IMFC and TWC over southern Mexico and northern Central America, following the second peak of precipitation.

A scatter plot of the mean changes to the IMFD, TWC and the CLLJ and their relationship to the synchronous variations in precipitation (Fig. 14) confirm that TWC and IMFC are strongly related to the timing and strength of the seasonal cycle of precipitation. The interannual variability of the precipitation differences MSD-P1 in ERA5 are very well explained by the variability of the TWC $(r=0.87)$ and the $\operatorname{IMFC}(r=-0.98)$ but less so by the CLLJ $(r=0.14)$. The inter-experiment MSD-P1 precipitation differences can largely be explained by the differences in IMFC changes during the MSD-P1 periods $(r=0.91)$. However, the changes in the CLLJ and IMFC in the simulations can not explain the precipitation differences between the runs in the MSD-P1 periods.

The changes from the MSD to the second peak of precipitation (Fig. 14) in the simulations are explained to some extent by the mean variations to the CLLJ and the IMFC but less so by changes in the TWC. However, for the interannual variability of precipitation changes (P2-MSD) in ERA5, only the TWC and IMFC show significant and relatively high correlations. These results would suggest that the observed interannual and inter-experiment variability of the CLLJ cannot explain the differences in the strength of the second peak of precipitation.

The synchronous relationship found in the previous scatterplot is further tested via 
lagged correlations (Fig. 15). These correlations do not show any evidence of robust relationship between the CLLJ and precipitation directly at any lags. as the correlation coefficients are not higher than 0.3 at any lag and only become significant for a few days in some simulations. In particular, around the MSDE date, no correlation at negative lags is significant and positive which is at odds with the hypothesis that CLLJ is responsible for the end of the MSD.

However, the strength of the CLLJ may not be the relevant factor, but rather the influence of the CLLJ on the IMFC. The correlation with the IMFC is positive and significant at lag 0 for both MSDO and MSDE dates, indicative that changes in precipitation during these periods are strongly correlated with the amount of moisture convergence in the column, as similar results are found for TWC-pr correlations (not shown). There is little evidence that this relationship is of a lagged nature, as the correlations are not significant away from the 0 lag.

The MSD is a key element of the climate of southern Mexico, northern Central America and the Caribbean, yet a comprehensive understanding of the processes for the seasonality of precipitation remains elusive. This study critically assessed three hypotheses that physically explain the MSD, using the MOHC CMIP6 experiments and the reanalysis ERA5. The diagnosis of MSD timing and patterns on a sub-monthly scale using the wavelet transform method (WT; García-Franco et al., 2021) to determine the timing of the MSD on a 5-day (pentad) scale is a step forward from previous studies that diagnosed the MSD on monthly-mean timescales. The WT method proved useful to separate the wet season in each dataset into three stages: the first and second peak periods (P1 and P2) and the drier period (MSD). This approach was able to reproduce the so-called "MSD patterns" reported in previous studies (Zermeño-Díaz, 2019, Zhao et al., 2020) using various diagnostics such as OLR, $\omega$ and the low-level winds.

The analysis of the leading hypotheses was carried out in two distinct manners. Firstly, ERA5 data were utilized to assess whether the given hypothesis could explain the interannual variability in the strength and timing of the MSD in the reanalysis. The second approach used data resulting from the MOHC CMIP6 experiments to test whether the elements of each hypothesis could explain the differences in the MSD strength and timing between different experiments.

The first mechanism proposed by Magaña et al. (1999) argues the Eastern Pacific SSTs should exhibit a bimodal seasonal cycle, with a second peak in SSTs found in September of similar magnitude to the early rainy season peak. Magaña and Caetano (2005) analysed the seasonal cycle of EP SSTs in a specific year and found no evidence of a late-summer increase in SSTs, yet, no study to date confirmed or denied their 
hypothesis. Evidence from our study shows that with ERA5 data, SSTs not only do not increase during the later stages of the summer, but, to the contrary, decrease. While the seasonal cycle in the model simulations shows a two-peak structure, no evidence is found that the variability in Eastern Pacific SSTs, or surface humidity, is directly associated with the precipitation over the MSD region in ERA5 nor in the CMIP6 experiments.

The solar declination angle hypothesis of Karnauskas et al. (2013) suggests that shortwave absorption has two peaks in the seasonal cycle following the solar declination angle, which leads to the two precipitation peaks. The shortwave absorption at the surface does show a bimodal seasonal cycle in ERA5 and in the simulations, as predicted by this mechanism. However, the interannual variability in ERA5 and inter-experiment differences exhibit an anti-correlation relationship between the absorbed shortwave and precipitation at the different stages of the rainy season. This means that years with a stronger shortwave absorption during the MSD are associated with drier second peak periods in ERA5 and experiments with less mean shortwave absorption show a wetter second peak, which appears to contradict this hypothesis.

Our study finds little evidence that these two radiative hypotheses can explain the observed or simulated MSD. The lack of a double-peak seasonal cycle in EP SSTs in ERA5, and the existence of an MSD signal in simulations that employ the observed SSTs as boundary conditions, seem to undermine the original argument presented by Magaña et al. (1999), as SST variability does not appear to be the dominant feature. Similarly, the solar declination angle hypothesis suggests a lagged positive correlation between solar insolation and precipitation around the MSD, yet our results indicate a syncrhonous negative correlation caused by CREs. Moreover, the present study reveals no robust changes to near-surface humidity in the EP nor the MSD, both of which are critical to these radiative hypotheses which argue that near-surface moisture drives precipitation variability on the MSD timescales.

The third hypothesis argues that the MSD is related to the CLLJ variability (Herrera et al., 2015, Zermeño-Díaz, 2019, Martinez et al., 2019). Synchronous changes to the zonal wind, the integrated moisture flux convergence (IMFC) and the precipitable water vapor suggest that the low-level wind flow in the Caribbean varies coherently with the stages of the MSD. Morevoer, the IMFC best explains the observed and simulated differences in precipitation, compared to the previous hypotheses. Strong correlations between the IMFC and precipitation suggest that the horizontal transport of moisture is a key element of the MSD mechanism.

Multiple roles have been attributed to the CLLJ as causal links to the MSD of the Pacific coast of Mesoamerica such as a modulation of moisture divergence (Durán-Quesada 
et al., 2017), cooling of SSTs (Herrera et al., 2015) and zonal circulations (Hidalgo et al., 2015). However, in this study, the CLLJ strength seems less skilful at predicting the strength of the MSD, in both model and reanalysis, compared to IMFC. Coherent and synchronous changes to the CLLJ are evident and may suggest that, as argued by Herrera et al. (2015), the CLLJ modulation of the moisture convergence is a key aspect of the MSD.

More generally, variability of the CLLJ and its influence over the regional moisture transport seem to be key for other aspects other than the MSD (Durán-Quesada et al., 2017 , ?). For example, evidence that the flow from the Caribbean Sea over the orography of the Mesoamerican region modulates convective activity in tropical cyclones (Fu et al., 2021), as well as the role of the CLLJ in teleconnection mechanisms from the Madden Julian Oscillation (MJO) (Martin and Schumacher, 2011, Perdigón-Morales et al., 2019) highlight the relevance of the low-level jet in the dynamics and precipitation variability. Our analysis of ERA5 and the MOHC CMIP6 experiments suggests that the CLLJ hypothesis best explains MSD characteristics, suggesting that dynamical mechanisms are more important than radiative mechanisms.

Questions still remain open such as how strong the influence of the CLLJ is on the horizontal moisture transport to the MSD region? The late summer warming of the Caribbean Sea and the strengthening of the CLLJ coinciding with the end of the MSD is consistent with the moisture transport hypothesis. The use of observational data to track temporal changes to the amount of precipitable water in the column in the MSD region may provide key insight into how strong is the influence of the CLLJ for MSD. On the modelling side, how the convective scheme represents the daily cycle of precipitation at each stage of the MSD remains to be compared to observations and understand its role in the seasonality of the MSD.

\section{References}

Adams, D. K. and Comrie, A. C. (1997), 'The north American monsoon', Bulletin of the American Meteorological Society 78(10), 2197-2214.

Allan, R. P. (2011), 'Combining satellite data and models to estimate cloud radiative effect at the surface and in the atmosphere', Meteorological Applications 18(3), 324333.

Amador, J. A. (2008), 'The intra-Americas sea low-level jet: Overview and future research', Annals of the New York Academy of Sciences 1146(1), 153-188. 
Amador, J. A., Alfaro, E. J., Lizano, O. G. and Magaña, V. O. (2006), 'Atmospheric forcing of the eastern tropical Pacific: A review', Progress in Oceanography 69(24), 101-142.

Amador, J. A., Durán-Quesada, A., Rivera, E., Mora, G., Sáenz, F., Calderón, B. and Mora, N. (2016), 'The easternmost tropical Pacific. Part II: Seasonal and intraseasonal modes of atmospheric variability', Revista de Biología Tropical pp. 23-57.

Anderson, T. G., Anchukaitis, K. J., Pons, D. and Taylor, M. (2019), 'Multiscale trends and precipitation extremes in the Central American Midsummer Drought', Environmental Research Letters 14(12), 124016.

Andrews, M., Ridley, J., Wood, R., Andrews, T., Blockley, E., Booth, B., Burke, E., Dittus, A., Florek, P., Gray, L., Haddad, S., Hardiman, S., Hermanson, L., Hodson, D., Hogan, E., Jones, G., Knight, J., Kuhlbrodt, T., Misios, S. and Sutton, R. (2020), 'Historical simulations with HadGEM3-GC3.1 for CMIP6', Journal of Advances in Modeling Earth Systems .

Angeles, M. E., González, J. E., Ramírez-Beltrán, N. D., Tepley, C. A. and Comarazamy, D. E. (2010), 'Origins of the Caribbean rainfall bimodal behavior', Journal of Geophysical Research: Atmospheres 115(D11).

Bony, S., Dufresne, J.-L., Le Treut, H., Morcrette, J.-J. and Senior, C. (2004), 'On dynamic and thermodynamic components of cloud changes', Climate Dynamics 22(23), 71-86.

Byrne, M. P. and Zanna, L. (2020), 'Radiative effects of clouds and water vapor on an axisymmetric monsoon', Journal of Climate 33(20), 8789-8811.

Cavazos, T., Luna-Niño, R., Cerezo-Mota, R., Fuentes-Franco, R., Méndez, M., Pineda Martinez, L. F. and Valenzuela, E. (2020), 'Climatic trends and regional climate models intercomparison over the CORDEX-CAM (Central America, Caribbean, and Mexico) domain', International Journal of Climatology 40(3), 1396-1420.

Cerón, W. L., Kayano, M. T., Andreoli, R. V., Avila-Diaz, A., de Souza, I. P. and Souza, R. A. (2021), 'Pacific and atlantic multidecadal variability relations with the choco and caribbean low-level jets during the 1900-2015 period', Atmosphere 12(9), 1120.

Chen, C., Son, N., Chen, C., Chiang, S., Chang, L. and Valdez, M. (2017), 'Drought monitoring in cultivated areas of central america using multi-temporal modis data', Geomatics, Natural Hazards and Risk 8(2), 402-417. 
Corrales-Suastegui, A., Fuentes-Franco, R. and Pavia, E. G. (2020), 'The mid-summer drought over Mexico and Central America in the 21st century', International Journal of Climatology 40(3), 1703-1715.

Curtis, S. (2002), 'Interannual variability of the bimodal distribution of summertime rainfall over Central America and tropical storm activity in the far-eastern Pacific', Climate Research 22, 141-146.

Curtis, S. and Gamble, D. W. (2008), 'Regional variations of the Caribbean mid-summer drought', Theoretical and Applied Climatology 94, 25-34.

Dilley, M. (1996), 'Synoptic controls on precipitation in the Valley of Oaxaca, Mexico', International Journal of Climatology: A Journal of the Royal Meteorological Society 16(9), 1019-1031.

Durán-Quesada, A. M., Gimeno, L. and Amador, J. (2017), 'Role of moisture transport for Central American precipitation', Earth System Dynamics 8(1), 147-161.

Durán-Quesada, A. M., Gimeno, L., Amador, J. and Nieto, R. (2010), 'Moisture sources for central america: Identification of moisture sources using a lagrangian analysis technique', Journal of Geophysical Research: Atmospheres 115(D5).

Eyring, V., Bony, S., Meehl, G. A., Senior, C. A., Stevens, B., Stouffer, R. J. and Taylor, K. E. (2016), 'Overview of the Coupled Model Intercomparison Project Phase 6 (CMIP6) experimental design and organization', Geoscientific Model Development (Online) 9.

Fu, D., Chang, P., Patricola, C. M., Saravanan, R., Liu, X. and Beck, H. E. (2021), 'Central american mountains inhibit eastern north pacific seasonal tropical cyclone activity', Nature communications 12(1), 1-11.

Fuentes-Franco, R., Coppola, E., Giorgi, F., Pavia, E. G., Diro, G. T. and Graef, F. (2015), 'Inter-annual variability of precipitation over Southern Mexico and Central America and its relationship to sea surface temperature from a set of future projections from CMIP5 GCMs and RegCM4 CORDEX simulations', Climate Dynamics 45(12), 425-440.

Funk, C., Peterson, P., Landsfeld, M., Pedreros, D., Verdin, J., Shukla, S., Husak, G., Rowland, J., Harrison, L., Hoell, A. and Michaelsen, J. (2015), 'The climate hazards infrared precipitation with stations - a new environmental record for monitoring extremes', Scientific data 2, 150066. 
Gamble, D. W., Parnell, D. B. and Curtis, S. (2008), 'Spatial variability of the Caribbean mid-summer drought and relation to north Atlantic high circulation', International Journal of Climatology 28(3), 343-350.

García-Franco, J. L., Osprey, S. and Gray, L. J. (2021), 'A wavelet transform method to determine monsoon onset and retreat from precipitation time-series', International Journal of Climatology 41(11), 5295-5317.

URL: https://rmets.onlinelibrary.wiley.com/doi/abs/10.1002/joc.7130

García-Franco, J. L., Gray, L. J. and Osprey, S. (2020), 'The American monsoon system in HadGEM3 and UKESM1', Weather and Climate Dynamics 1(2), 349-371.

URL: https://wcd.copernicus.org/articles/1/349/2020/

García-Martínez, I. M. and Bollasina, M. A. (2020), 'Sub-monthly evolution of the Caribbean Low-Level Jet and its relationship with regional precipitation and atmospheric circulation', Climate Dynamics 54(9), 4423-4440.

Giannini, A., Kushnir, Y. and Cane, M. A. (2000), 'Interannual variability of Caribbean rainfall, ENSO, and the Atlantic Ocean', Journal of Climate 13, 297-311.

Good, P., Chadwick, R., Holloway, C. E., Kennedy, J., Lowe, J. A., Roehrig, R. and Rushley, S. S. (2021), 'High sensitivity of tropical precipitation to local sea surface temperature', Nature 589(7842), 408-414.

Gregory, D. and Rowntree, P. (1990), 'A mass flux convection scheme with representation of cloud ensemble characteristics and stability-dependent closure', Monthly Weather Review 118(7), 1483-1506.

Guo, Z., Zhou, T., Wang, M. and Qian, Y. (2015), 'Impact of cloud radiative heating on East Asian summer monsoon circulation', Environmental Research Letters 10(7), 074014.

Harvey, C. A., Saborio-Rodríguez, M., Martinez-Rodríguez, M. R., Viguera, B., ChainGuadarrama, A., Vignola, R. and Alpizar, F. (2018), 'Climate change impacts and adaptation among smallholder farmers in Central America', Agriculture $\& 5$ Food Security $7(1), 57$.

Hastenrath, S. L. (1967), 'Rainfall distribution and regime in Central America', Archiv für Meteorologie, Geophysik und Bioklimatologie, Serie B 15(3), 201-241. 
Hellin, J., Cox, R. and López-Ridaura, S. (2017), 'Maize Diversity, Market Access, and Poverty Reduction in the Western Highlands of Guatemala', Mountain Research and Development 37(2), 188 - 197.

Herrera, E., Magaña, V. and Caetano, E. (2015), 'Air-sea interactions and dynamical processes associated with the midsummer drought', International Journal of Climatology 35(7), 1569-1578.

Hersbach, H., Bell, B., Berrisford, P., Hirahara, S., Horányi, A., Muñoz-Sabater, J., Nicolas, J., Peubey, C., Radu, R., Schepers, D., Simmons, A., Soci, C., Abdalla, S., Abellan, X., Balsamo, G., Bechtold, P., Biavati, G., Bidlot, J., Bonavita, M., De Chiara, G., Dahlgren, P., Dee, D., Diamantakis, M., Dragani, R., Flemming, J., Forbes, R., Fuentes, M., Geer, A., Haimberger, L., Healy, S., Hogan, R. J., Hólm, E., Janisková, M., Keeley, S., Laloyaux, P., Lopez, P., Lupu, C., Radnoti, G., de Rosnay, P., Rozum, I., Vamborg, F., Villaume, S. and Thépaut, J.-N. (2020), 'The ERA5 global reanalysis', Quarterly Journal of the Royal Meteorological Society 146(730), 1999-2049.

Hidalgo, H. G., Durán-Quesada, A. M., Amador, J. A. and Alfaro, E. J. (2015), 'The caribbean low-level jet, the inter-tropical convergence zone and precipitation patterns in the intra-americas sea: a proposed dynamical mechanism', Geografiska Annaler: Series A, Physical Geography 97(1), 41-59.

URL: https://doi.org/10.1111/geoa.12085

Huffman, G. J., Adler, R. F., Bolvin, D. T. and Nelkin, E. J. (2010), The TRMM multisatellite precipitation analysis (TMPA), in 'Satellite rainfall applications for surface hydrology', Springer, pp. 3-22.

Imbach, P., Chou, S. C., Lyra, A., Rodrigues, D., Rodriguez, D., Latinovic, D., Siqueira, G., Silva, A., Garofolo, L. and Georgiou, S. (2018), 'Future climate change scenarios in central america at high spatial resolution', PLoS One 13(4), e0193570.

Jobbová, E., Helmke, C. and Bevan, A. (2018), 'Ritual responses to drought: An examination of ritual expressions in Classic Maya written sources', Human Ecology 46(5), 759-781.

Karnauskas, K. B., Seager, R., Giannini, A. and Busalacchi, A. J. (2013), 'A simple mechanism for the climatological midsummer drought along the Pacific coast of Central America', Atmósfera 26, 261-281. 
Magaña, V., Amador, J. A. and Medina, S. (1999), 'The midsummer drought over Mexico and Central America', Journal of Climate 12, 1577-1588.

Magaña, V. and Caetano, E. (2005), 'Temporal evolution of summer convective activity over the Americas warm pools', Geophysical Research Letters 32(2).

Maldonado, T., Rutgersson, A., Alfaro, E., Amador, J. and Claremar, B. (2016), 'Interannual variability of the midsummer drought in central america and the connection with sea surface temperatures', Advances in Geosciences 42, 35-50.

Mapes, B. E., Liu, P. and Buenning, N. (2005), 'Indian monsoon onset and the Americas midsummer drought: Out-of-equilibrium responses to smooth seasonal forcing', Journal of Climate 18(7), 1109-1115.

Martin, E. R. and Schumacher, C. (2011), 'Modulation of caribbean precipitation by the madden-julian oscillation', Journal of Climate 24(3), 813-824.

Martinez, C., Goddard, L., Kushnir, Y. and Ting, M. (2019), 'Seasonal climatology and dynamical mechanisms of rainfall in the caribbean', Climate dynamics 53(1-2), 825846.

Maurer, E. P., Roby, N., Stewart-Frey, I. T. and Bacon, C. M. (2017), 'Projected twentyfirst-century changes in the central american mid-summer drought using statistically downscaled climate projections', Regional Environmental Change 17(8), 2421-2432.

Menary, M. B., Kuhlbrodt, T., Ridley, J., Andrews, M. B., Dimdore-Miles, O. B., Deshayes, J., Eade, R., Gray, L., Ineson, S., Mignot, J., Roberts, C. D., Robson, J., Wood, R. A. and Xavier, P. (2018), 'Preindustrial control simulations with HadGEM3-GC3. 1 for CMIP6', Journal of Advances in Modeling Earth Systems 10(12), 3049-3075.

Mosiño, A. and García, E. (1966), Evaluación de la sequía intraestival en la República Mexicana, in 'Proc. Conf. Reg. Latinoamericana Unión Geogr. Int', Vol. 3, pp. 500-516.

Mulcahy, J. P., Jones, C., Sellar, A., Johnson, B., Boutle, I. A., Jones, A., Andrews, T., Rumbold, S. T., Mollard, J., Bellouin, N., Johnson, C. E., Williams, K. D., Grosvenor, D. P. and McCoy, D. T. (2018), 'Improved aerosol processes and effective radiative forcing in HadGEM3 and UKESM1', Journal of Advances in Modeling Earth Systems 10(11), 2786-2805.

Muñoz, E., Busalacchi, A. J., Nigam, S. and Ruiz-Barradas, A. (2008), 'Winter and summer structure of the Caribbean low-level jet', Journal of Climate 21(6), 12601276. 
Perdigón-Morales, J., Romero-Centeno, R., Barrett, B. S. and Ordoñez, P. (2019), 'Intraseasonal variability of summer precipitation in Mexico: MJO influence on the midsummer drought', Journal of Climate 32(8).

Perdigón-Morales, J., Romero-Centeno, R., Ordóñez, P. and Barrett, B. S. (2018), 'The midsummer drought in Mexico: perspectives on duration and intensity from the CHIRPS precipitation database', International Journal of Climatology 38, 2174-2186.

Rauscher, S. A., Giorgi, F., Diffenbaugh, N. S. and Seth, A. (2008), 'Extension and intensification of the Meso-American mid-summer drought in the twenty-first century', Climate Dynamics 31, 551-571.

Ridley, J., Menary, M., Kuhlbrodt, T., Andrews, M. and Andrews, T. (2019a), 'Mohc hadgem3-gc31-ll model output prepared for cmip6 cmip amip'.

URL: https://doi.org/10.22033/ESGF/CMIP6.5853

Ridley, J., Menary, M., Kuhlbrodt, T., Andrews, M. and Andrews, T. (2019b), 'MOHC HadGEM3-GC31-MM model output prepared for CMIP6 CMIP piControl'.

URL: https://doi.org/10.22033/ESGF/CMIP6.6297

Ryu, J.-H. and Hayhoe, K. (2014), 'Understanding the sources of Caribbean precipitation biases in CMIP3 and CMIP5 simulations', Climate dynamics 42(11-12), 3233-3252.

Sellar, A. A., Jones, C. G., Mulcahy, J., Tang, Y., Yool, A., Wiltshire, A., O'Connor, F. M., Stringer, M., Hill, R., Palmieri, J., Woodward, S., de Mora, L., Kuhlbrodt, T., Rumbold, S., Kelley, D. I., Ellis, R., Johnson, C. E., Walton, J., Abraham, N. L., Andrews, M. B., Andrews, T., Archibald, A. T., Berthou, S., Burke, E., Blockley, E., Carslaw, K., Dalvi, M., Edwards, J., Folberth, G. A., Gedney, N., Griffiths, P. T., Harper, A. B., Hendry, M. A., Hewitt, A. J., Johnson, B., Jones, A., Jones, C. D., Keeble, J., Liddicoat, S., Morgenstern, O., Parker, R. J., Predoi, V., Robertson, E., Siahaan, A., Smith, R. S., Swaminathan, R., Woodhouse, M. T., Zeng, G. and Zerroukat, M. (2019), 'UKESM1: Description and evaluation of the UK Earth System Model', Journal of Advances in Modeling Earth Systems 11(12), 4513-4558.

Small, R. J. O., De Szoeke, S. P. and Xie, S.-P. (2007), 'The Central American midsummer drought: Regional aspects and large-scale forcing', Journal of Climate 20(19), 48534873. 
Straffon, A., Zavala-Hidalgo, J. and Estrada, F. (2019), 'Preconditioning of the precipitation interannual variability in southern Mexico and Central America by oceanic and atmospheric anomalies', International Journal of Climatology .

Tang, Y., Rumbold, S., Ellis, R., Kelley, D., Mulcahy, J., Sellar, A., Walton, J. and Jones, C. (2019a), 'MOHC UKESM1.0-LL model output prepared for CMIP6 CMIP historical'.

URL: https://doi.org/10.22033/ESGF/CMIP6.6113

Tang, Y., Rumbold, S., Ellis, R., Kelley, D., Mulcahy, J., Sellar, A., Walton, J. and Jones, C. (2019b), 'MOHC UKESM1.0-LL model output prepared for CMIP6 CMIP piControl'.

URL: https://doi.org/10.22033/ESGF/CMIP6.6298

Walters, D., Boutle, I., Brooks, M., Melvin, T., Stratton, R., Vosper, S., Wells, H., Williams, K., Wood, N., Allen, T., Bushell, A., Copsey, D., Earnshaw, P., Edwards, J., Gross, M., Hardiman, S., Harris, C., Heming, J., Klingaman, N., Levine, R., Manners, J., Martin, G., Milton, S., Mittermaier, M., Morcrette, C., Riddick, T., Roberts, M., Sanchez, C., Selwood, P., Stirling, A., Smith, C., Suri, D., Tennant, W., Vidale, P. L., Wilkinson, J., Willett, M., Woolnough, S. and Xavier, P. (2019), 'The Met Office Unified Model global atmosphere 7.0/7.1 and JULES global land 7.0 configurations', Geoscientific Model Development 12(5), 1909-1963.

Webb, M. J., Andrews, T., Bodas-Salcedo, A., Bony, S., Bretherton, C. S., Chadwick, R., Chepfer, H., Douville, H., Good, P., Kay, J. E. et al. (2017), 'The cloud feedback model intercomparison project (CFMIP) contribution to CMIP6', Geoscientific Model Development 10(1), 359-384.

Williams, K. D., Copsey, D., Blockley, E. W., Bodas-Salcedo, A., Calvert, D., Comer, R., Davis, P., Graham, T., Hewitt, H. T., Hill, R., Hyder, P., Ineson, S., Johns, T. C., Keen, A. B., Lee, R. W., Megann, A., Milton, S. F., Rae, J. G. L., Roberts, M. J., Scaife, A. A., Schiemann, R., Storkey, D., Thorpe, L., Watterson, I. G., Walters, D. N., West, A., Wood, R. A., Woollings, T. and Xavier, P. K. (2018), 'The Met Office global coupled model 3.0 and 3.1 (GC3. 0 and GC3. 1) configurations', Journal of Advances in Modeling Earth Systems 10(2), 357-380.

Yang, B., Zhang, Y., Qian, Y., Song, F., Leung, L. R., Wu, P., Guo, Z., Lu, Y. and Huang, A. (2019), 'Better monsoon precipitation in coupled climate models due to bias compensation', NPJ Climate and Atmospheric Science 2(1), 1-8. 
Zermeño-Díaz, D. M. (2019), 'The spatial pattern of midsummer drought as a possible mechanistic response to lower-tropospheric easterlies over the intra-americas seas', Journal of Climate 32(24), 8687-8700.

Zhao, Z., Holbrook, N. J., Oliver, E. C., Ballestero, D. and Vargas-Hernandez, J. M. (2020), 'Characteristic atmospheric states during mid-summer droughts over Central America and Mexico', Climate Dynamics pp. 1-21.

Zhao, Z. and Zhang, X. (2021), 'Evaluation of methods to detect and quantify the bimodal precipitation over Central America and Mexico', International Journal of Climatology 41, E897-E911.

\section{Declarations}

Funding

J.L.G.F was supported by an Oxford-Richards graduate scholarship under Wadham College, and by a Met Office-Partnership PhDCASE studentship. Funding for the authors is from Natural Environment Research Council, Grant/Award Number: NE/P006779/1; NERC North Atlantic Climate System Integrated Study (ACSIS), Grant/Award Number: NE/N018028 Sections.

\section{Competing interests}

All authors declare that they have no competing interests.

\section{Author contributions}

JLGF designed and conducted the analyses. RC, SO and LJG directed the research and JLGF, DKA and RC prepared the written manuscript.

\section{Data availability statement}

All data used in this study is publicly available. ERA5 reanalysis data are available from the Copernicus Climate Change Service Climate Data Store (CDS, https:// climate.copernicus.eu/climate-reanalysis, C3S, 2017). CMIP6 simulations used in this study are available from the Earth System Grid Federation of the Centre for Environmental Data Analysis (ESGF-CEDA; https://esgf-index1.ceda.ac.uk/projects/ cmip6-ceda/, WRP, 2019, last access: 2 Oct 2021). TRMM 3B42 were obtained from at https://https://disc.gsfc.nasa.gov/datasets/TRMM_3B42_Daily_7/, last accessed Nov 11, 2021.

\section{Supplementary Material}



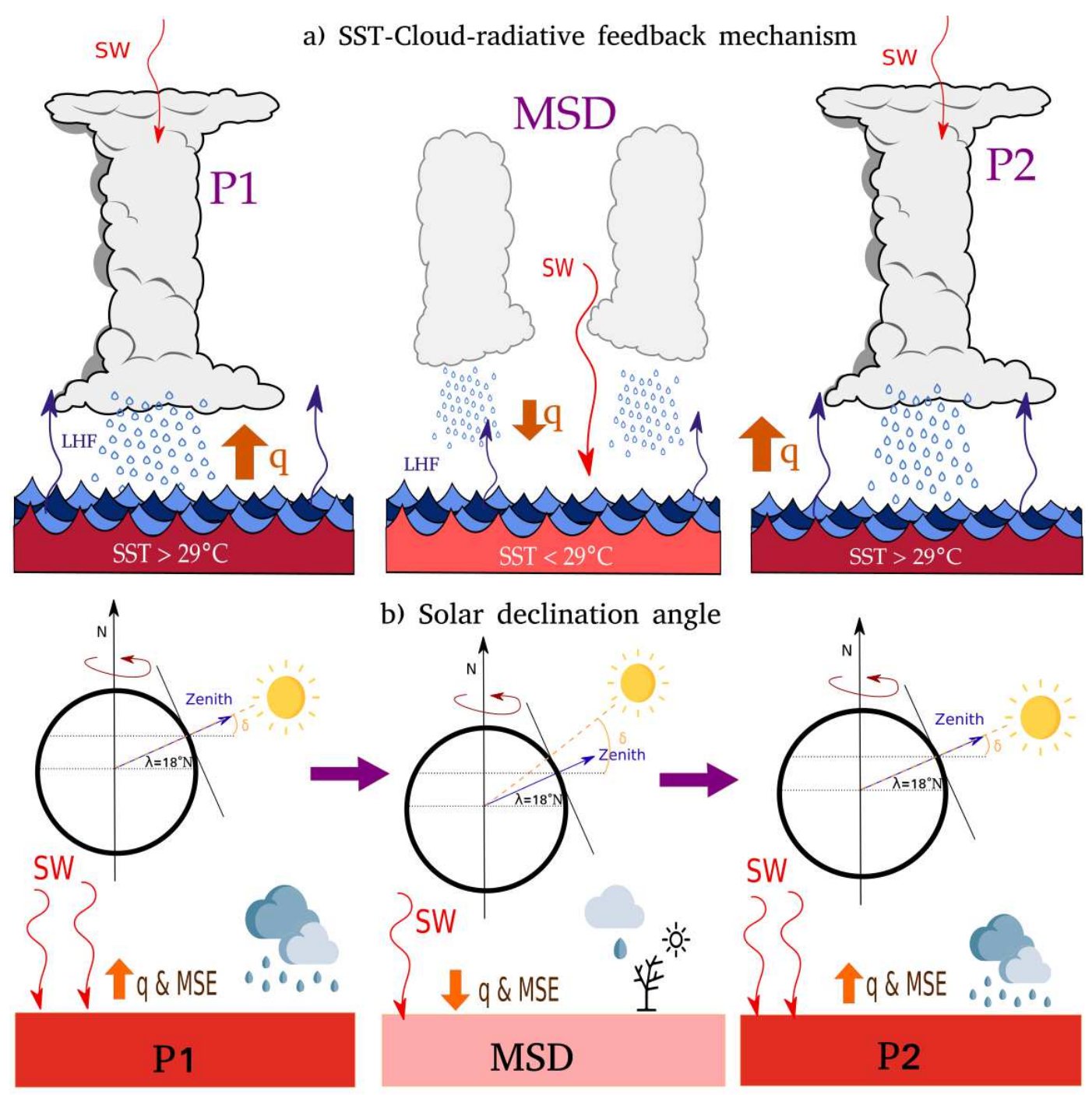

b) Solar declination angle

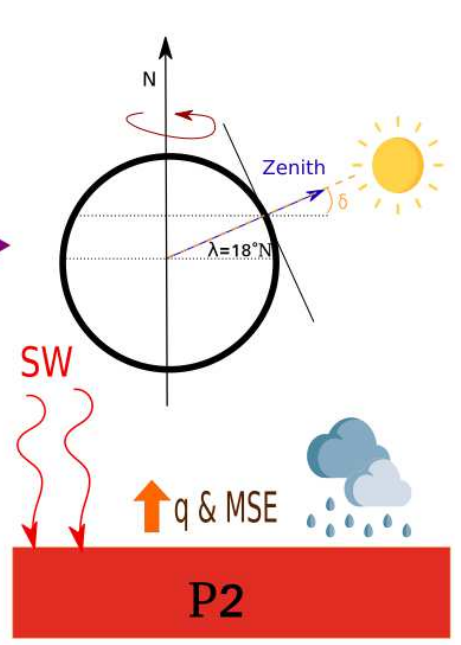

c) Caribbean Low-Level Jet Moisture Transport

P1, P2 wet periods (Jun, Sep)
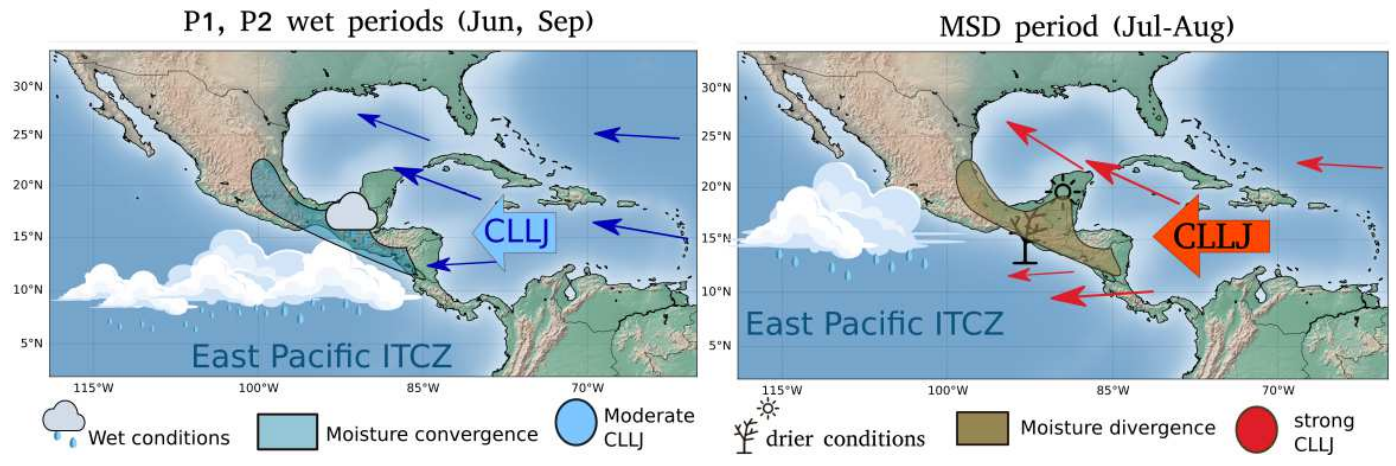

Figure 1: Schematic of the three mechanisms analysed in this paper, a) the SST cloud-radiative mechanism, (b) the solar declination angle and (c) the moisture divergence mechanism driven by the CLLJ. In all panels, the three stages of the MSD are represented: the first peak period (P1), the MSD and the second peak period (P2). 


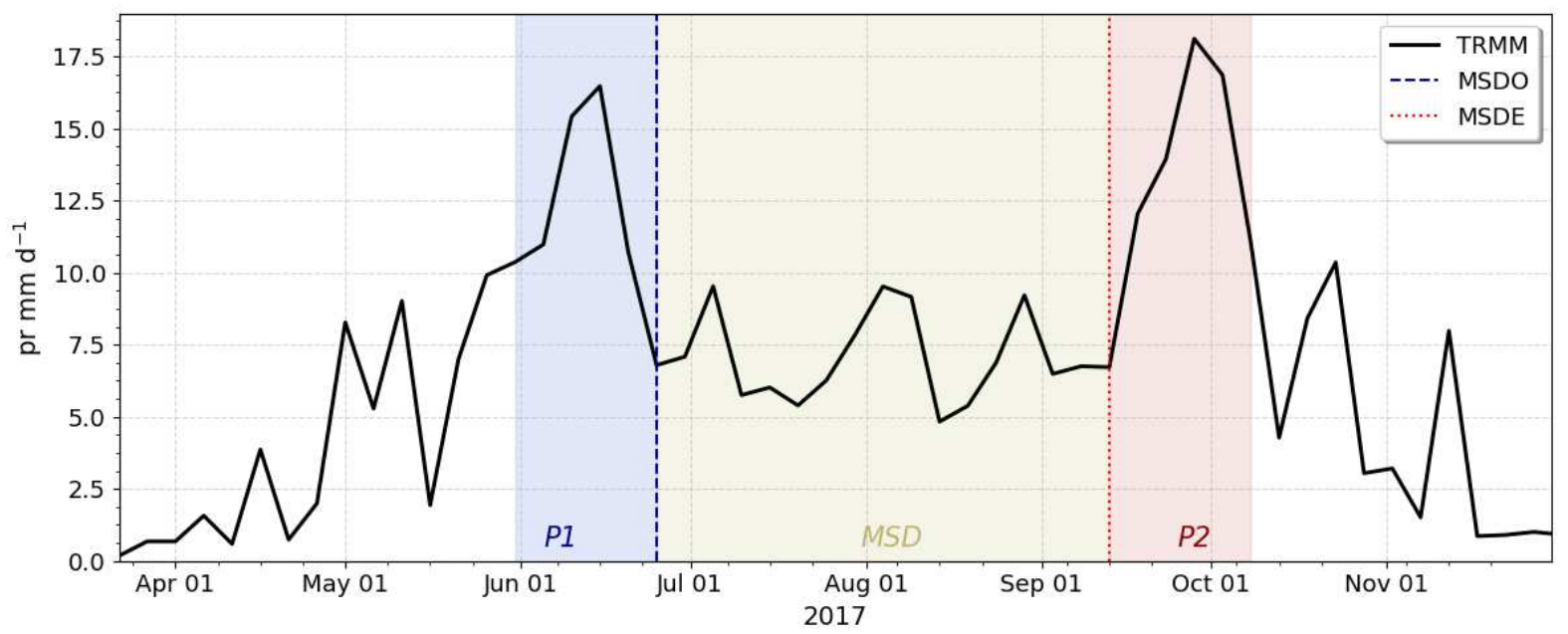

Figure 2: Pentad-mean precipitation averaged over the study region $\left[95-86^{\circ} \mathrm{W}, 11-19^{\circ} \mathrm{N}\right]$ in the TRMM dataset for the summer of 2017. The timing of the onset (MSDO) and end (MSDE) of the MSD, as well as the first (P1) and second (P2) peak periods and the MSD periods are highlighted. 

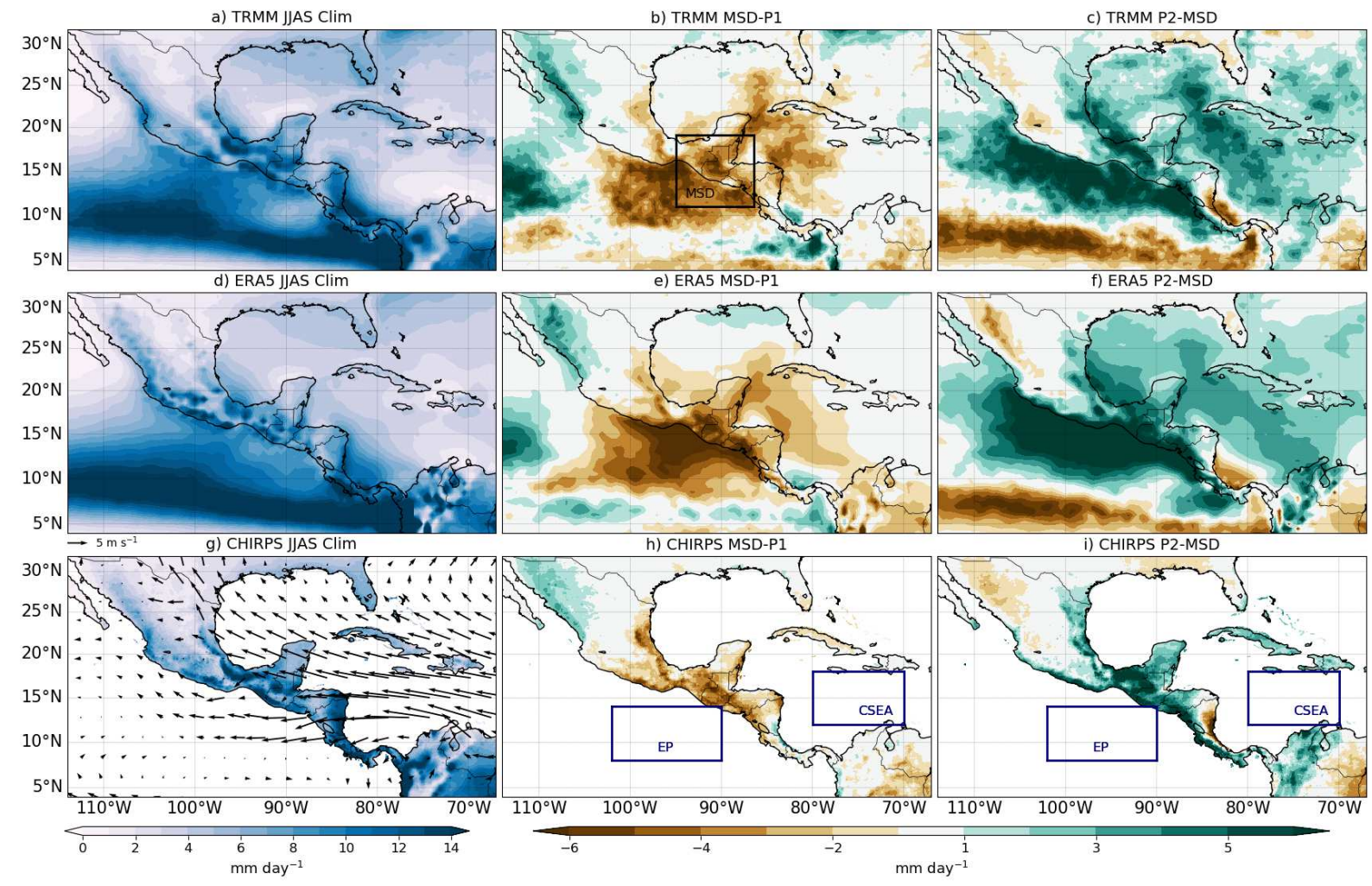

Figure 3: (a, d, g) Climatological JJAS rainfall and the difference (b, e, h) between the midsummer drought and the first peak (MSD-P1) periods and (c, f, i) between the second peak and the midsummer drought (P2-MSD) periods for (a-c) TRMM, (d-f) ERA5 and (g-i) CHIRPS. The climatological lowlevel winds (at $850 \mathrm{hPa}$ ) for JJAS in ERA5 are shown in c). The boxes in panels $\mathrm{b}, \mathrm{h}$ and $\mathrm{i}$ show the definitions of the MSD, Eastern Pacific (EP) and Caribbean Sea (CSEA) regions that are used throughout this paper. 
a)

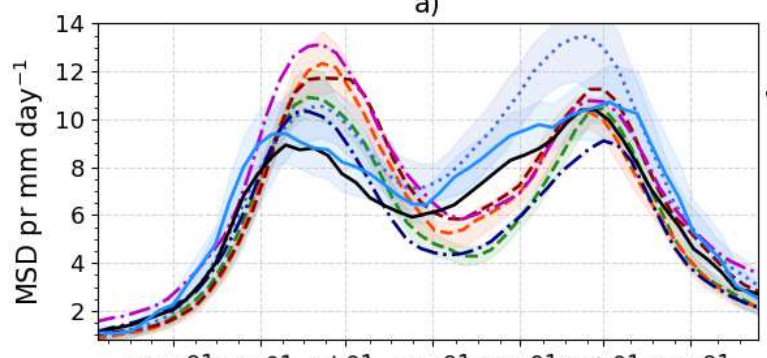

May 01 Jun 01 Jul 01 Aug 01 Sep 01 oct 01 Nov 01 C)

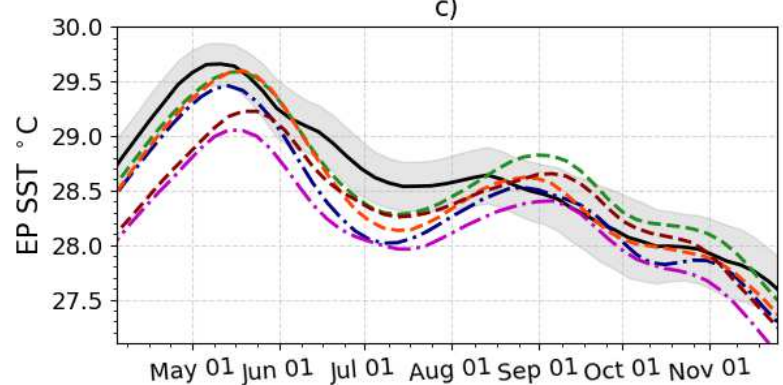

e)

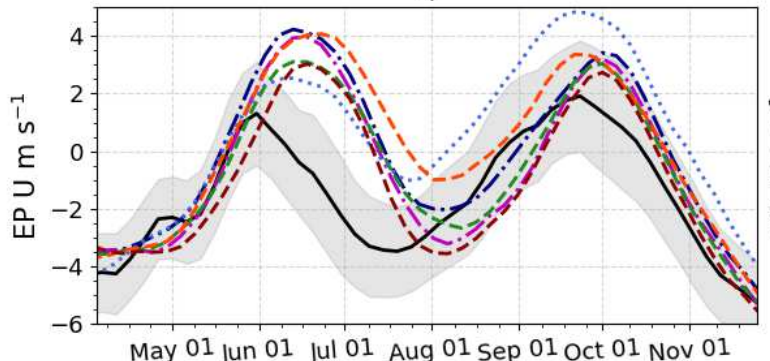

--- GC31-LL hist --- GC31-MM hist

--- UKESM-hist ...... GC31-LL amip b)

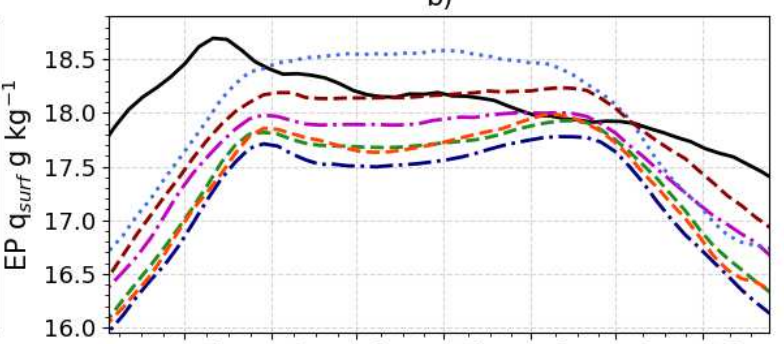

May 01 Jun 01 Jul 01 Aug 01 sep 01 oct 01 Nov 01

d)

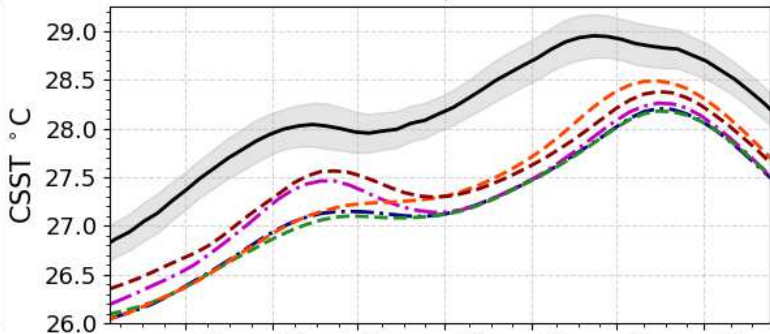

May 01 Jun 01 Jul 01 Aug 01 sep 01 oct 01 Nov 01

f)

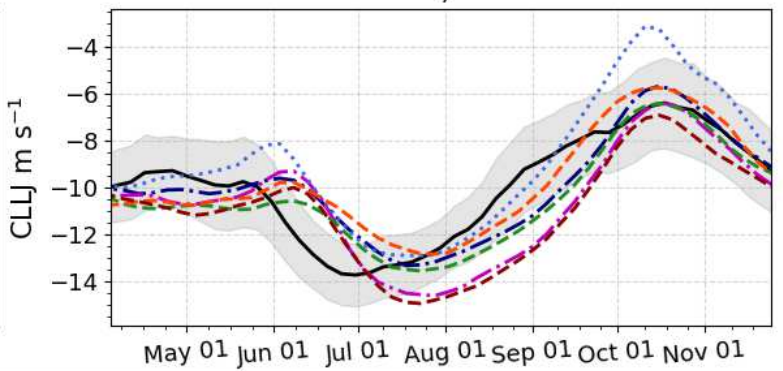

May 01 Jun 01 Jul 01 Aug 01 Sep 01 oct 01 Nov 01

Figure 4: Pentad-mean seasonal march of (a) MSD precipitation, (b) EP near-surface humidity, (c) EP SSTs $\left[{ }^{\circ} \mathrm{C}\right]$, (d) CSEA SSTs, and the low-level (925-hPa) zonal wind flow $\left[\mathrm{m} \mathrm{s}^{-1}\right]$ in (e) the EP and (f) the CSEA regions. The areas for the regions used are illustrated in Figure 3. 
a) ERA-5 MSD-P1

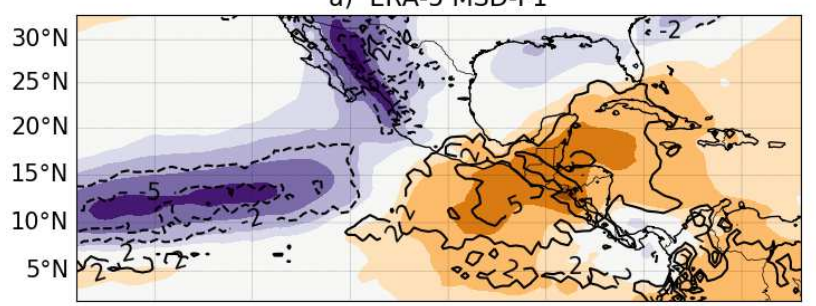

c) GC31-LL hist MSD-P1

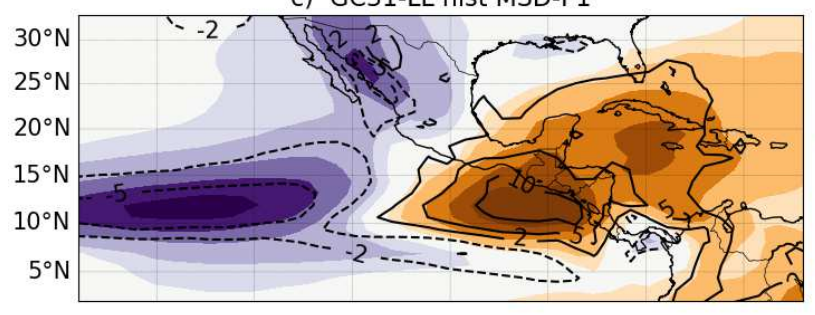

e) GC31-MM hist MSD-P1

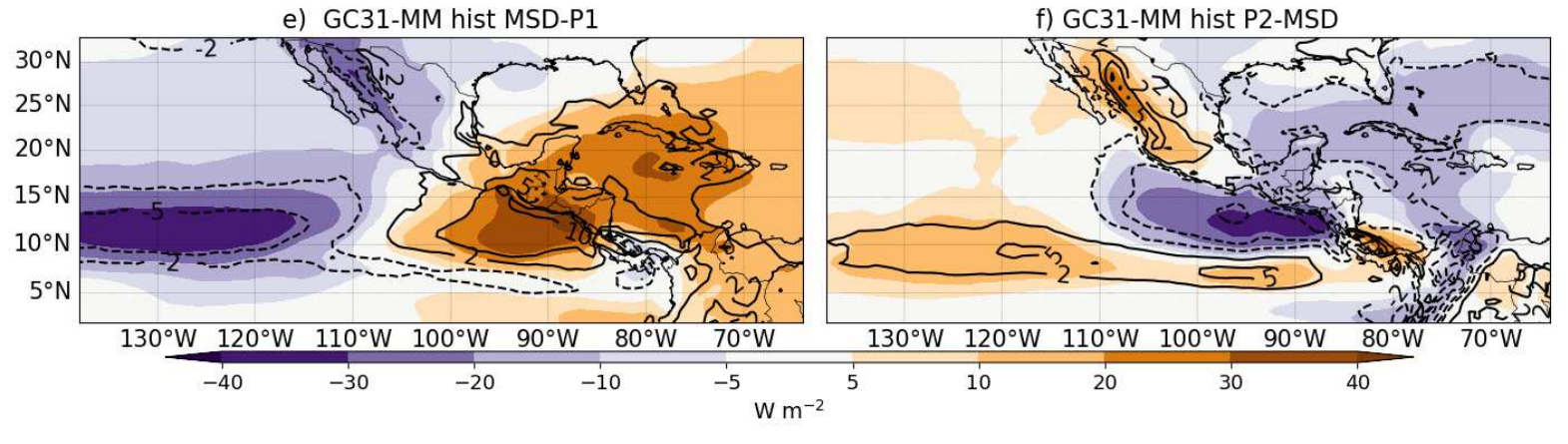

b) ERA-5 P2-MSD

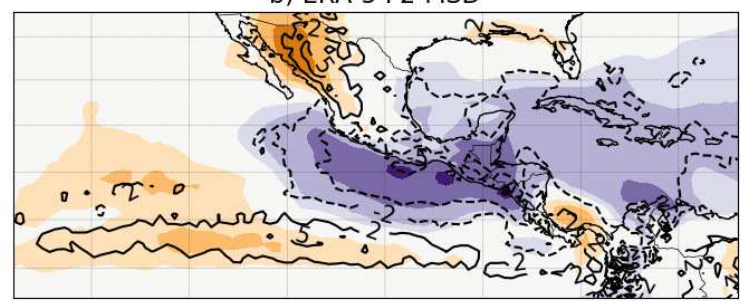

d) GC31-LL hist P2-MSD

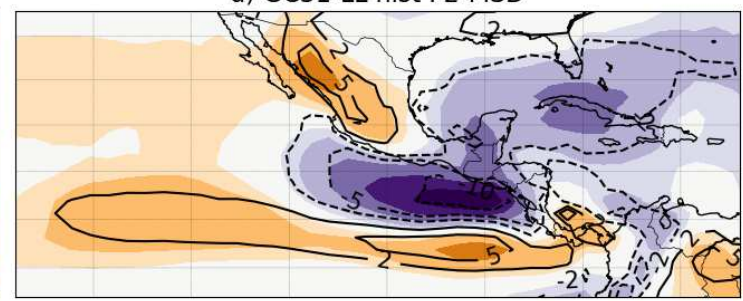

f) GC31-MM hist P2-MSD 
a) ERA-5 MSD-P1

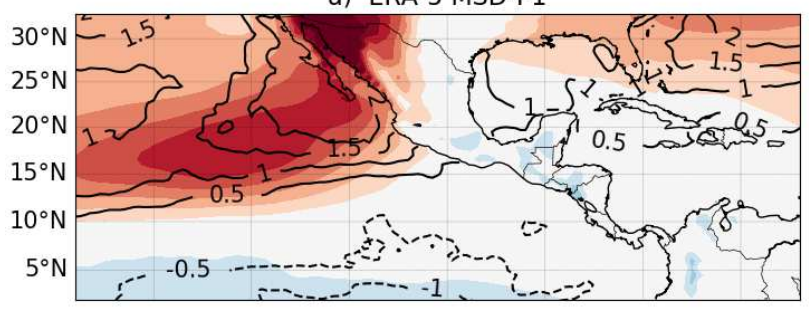

c) GC31-LL hist MSD-P1

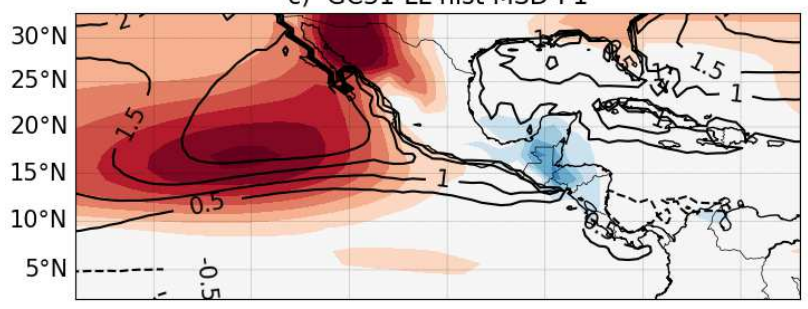

e) GC31-MM hist MSD-P1

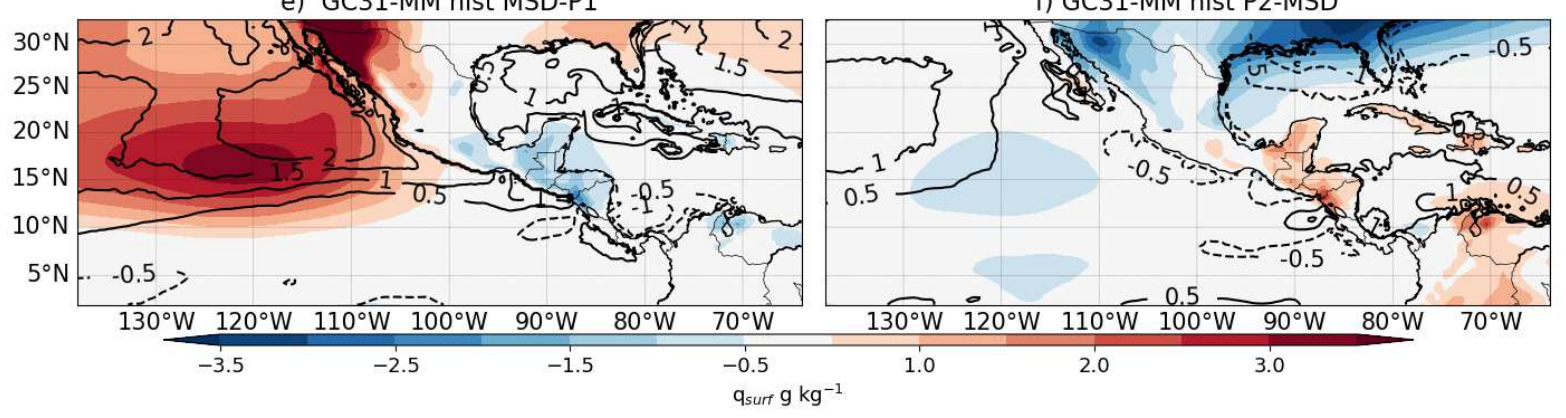

b) ERA-5 P2-MSD

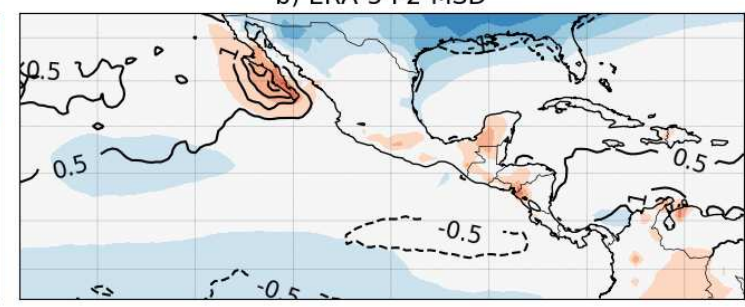

d) GC31-LL hist P2-MSD

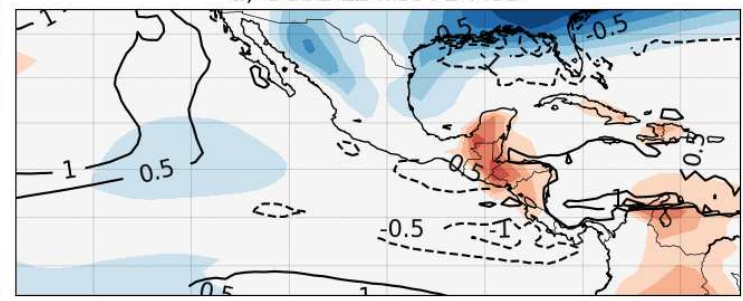

f) GC31-MM hist P2-MSD

Figure 6: As in Figure 5 but the anomalies are shown for near-surface humidity $\left[\mathrm{g} \mathrm{kg}^{-1}\right]$ (contours) and SSTs $[\mathrm{K}]$ (line-contours). 

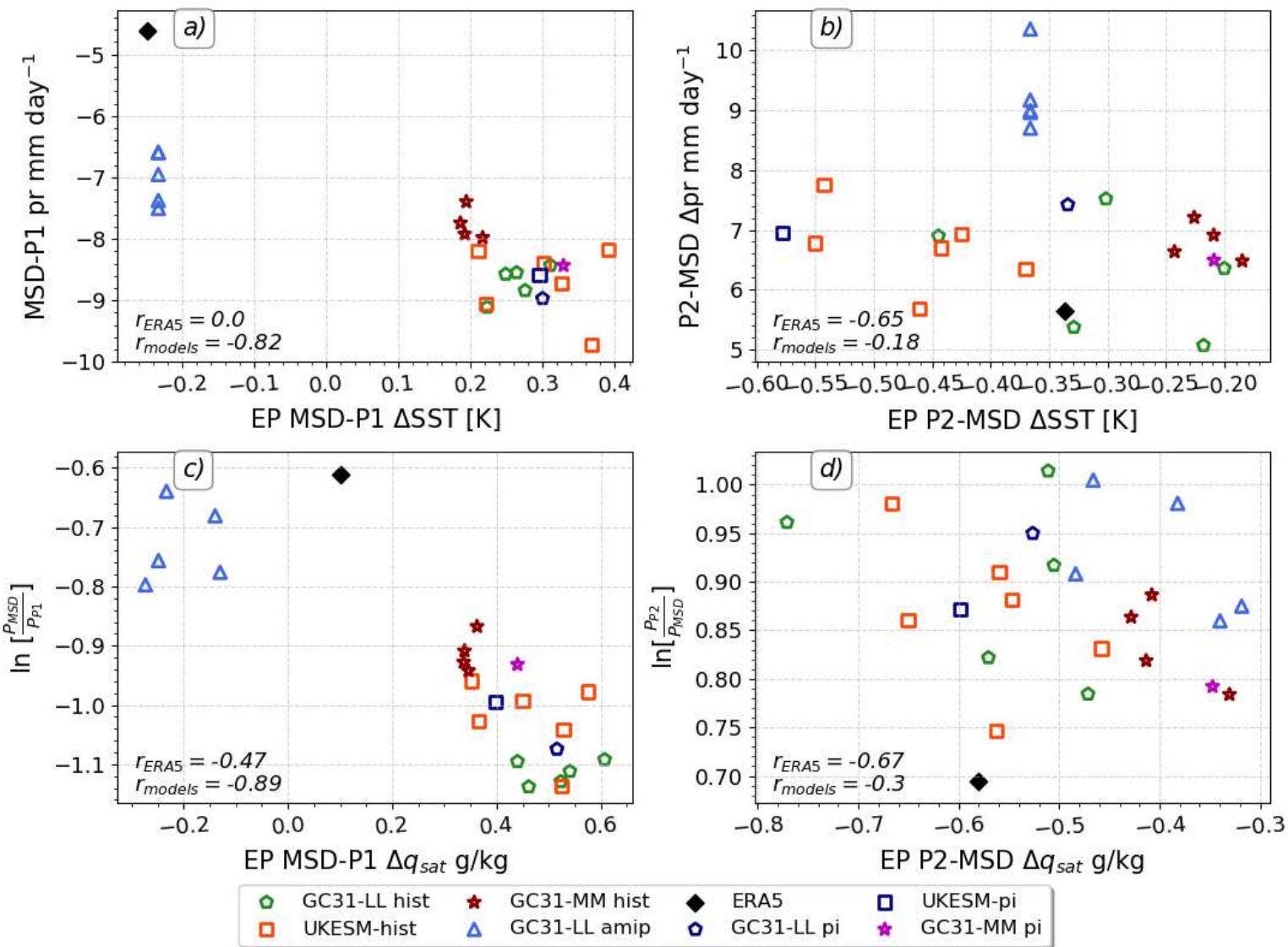

Figure 7: Scatterplots of the mean changes in the Eastern Pacific (a, b) sea-surface temperatures (SSTs) and $(\mathrm{c}, \mathrm{d})$ surface saturation specific humidity $\mathrm{q}_{\text {sat }}$ in the $\mathrm{x}$-axis with respect to precipitation variations in the MSD region on the y-axis for the (a, c) MSD-P1 and (b, d) P2-MSD periods. The correlation coefficients for ERA5 indicate the correlation of the sample of all the years, whereas the marker for ERA5 indicates the mean differences for variables in the $\mathrm{x}$ and $\mathrm{y}$-axis. The multi-experiment correlation coefficient is also shown in each panel. 

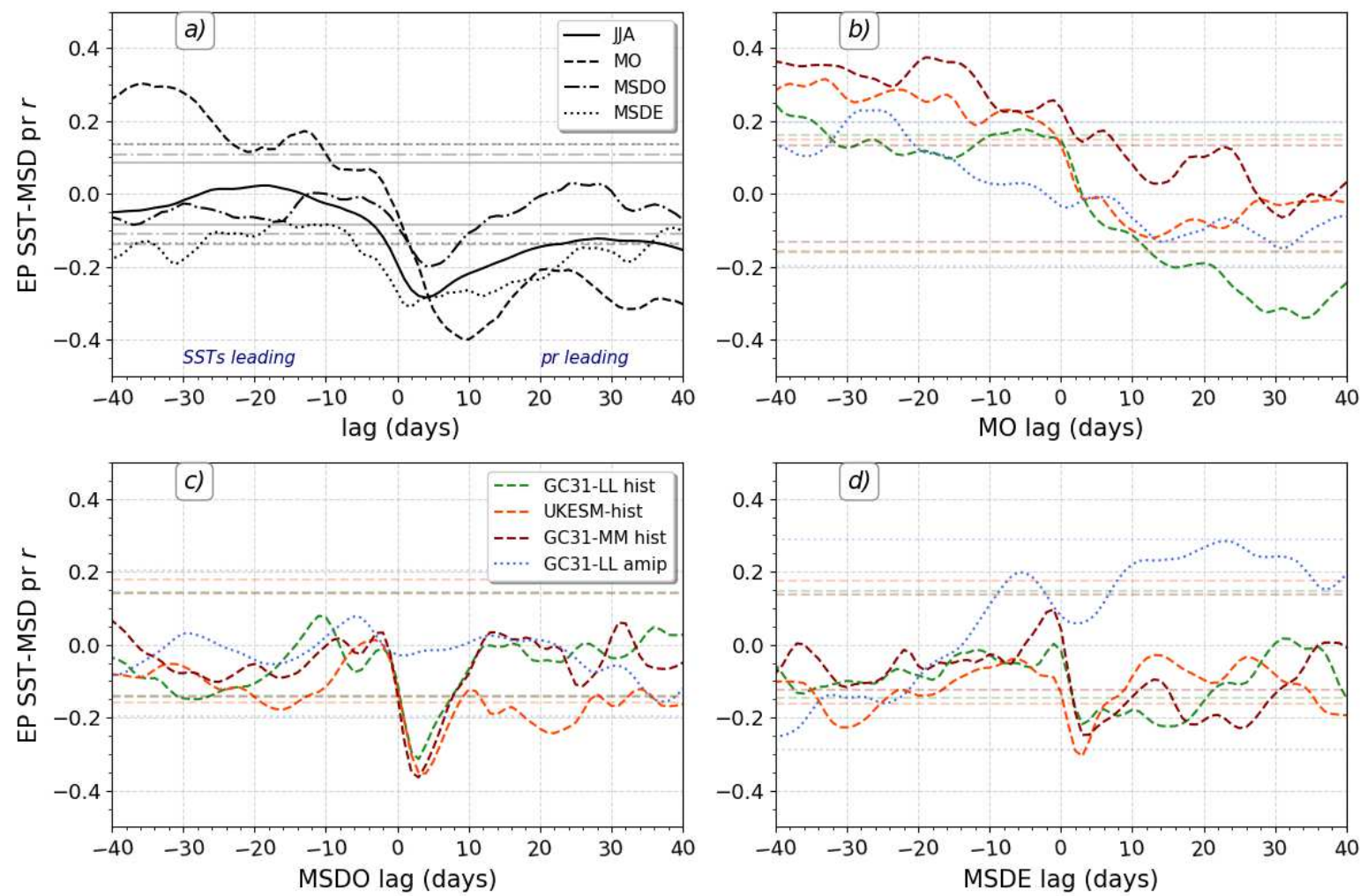

Figure 8: Lagged correlations between Eastern Pacific SSTs and precipitation in the MSD region for (a) ERA5 where the lag 0 date was used in four different ways: firstly, all the boreal summer JJAS SSTs and precipitation pairings, then lag 0 represents the monsoon onset (MO), MSD onset (MSDO) and MSDE dates. (b-d) as in (a), but for the simulations where the correlations are computed with the SST-precipitation timeseries lagged with respect to the b) monsoon onset date, the c) MSDO date and the d) MSDE date. 

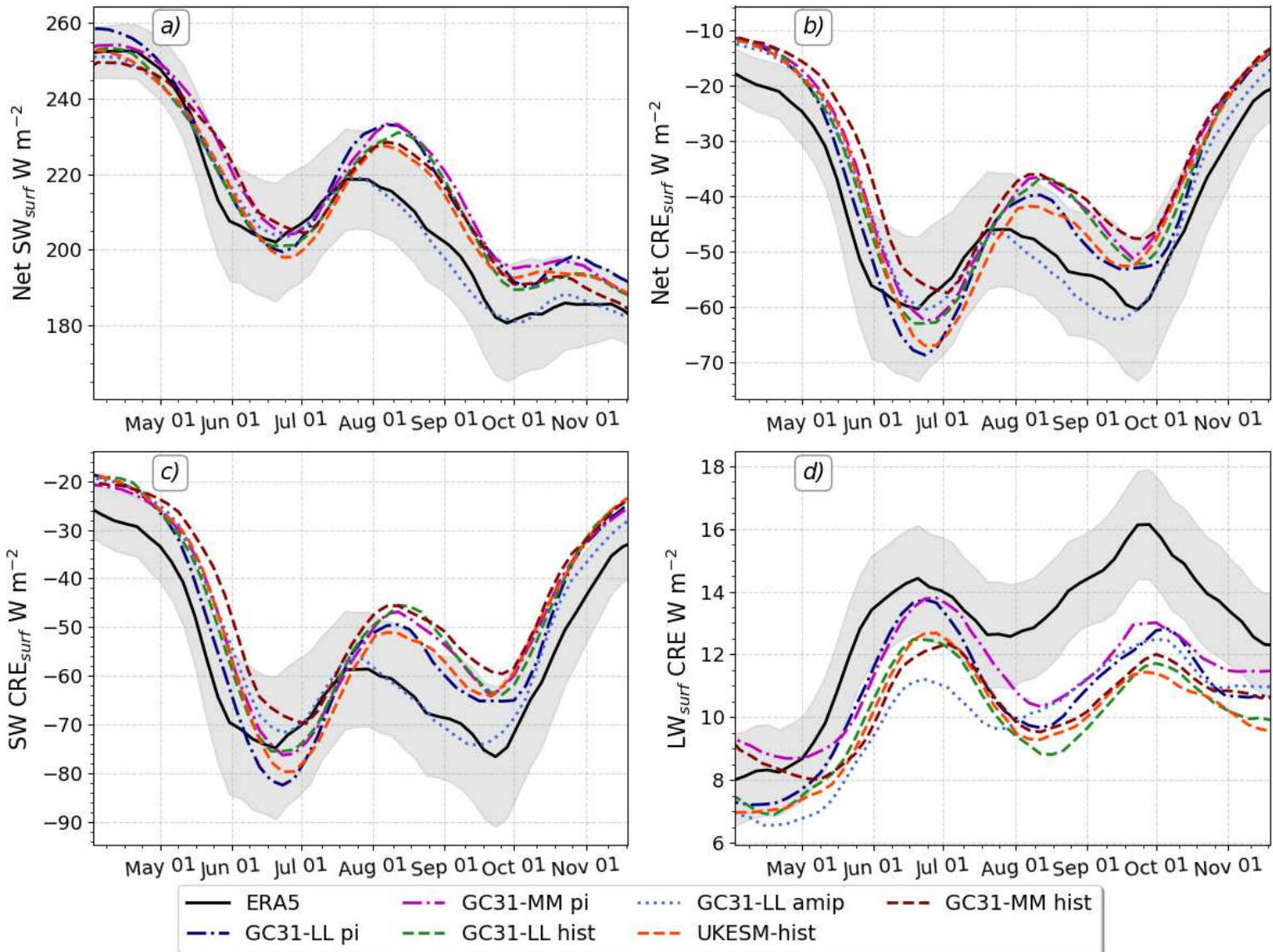

Figure 9: Pentad-mean seasonal cycle of the (a) the net SW at the surface, signed positive to indicate surface absorption of SW radiation, and (b) the net CRE, (c) SW and (d) LW CREs at the surface, averaged over the MSD region. 
a) ERA-5 MSD-P1

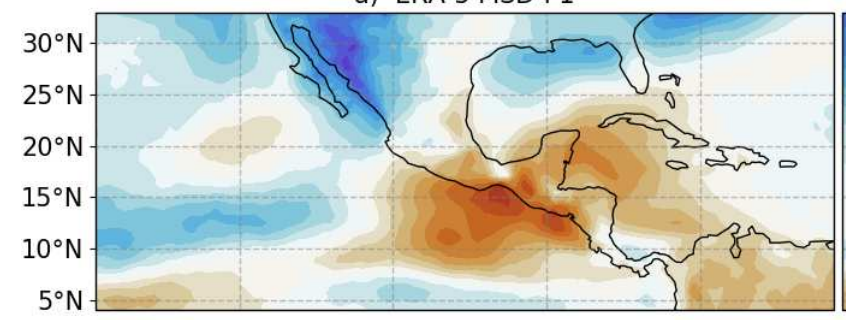

c) GC31-LL hist MSD-P1

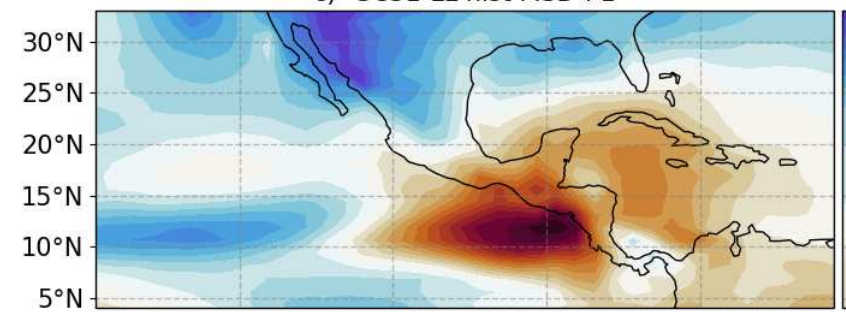

e) UKESM1-hist MSD-P1

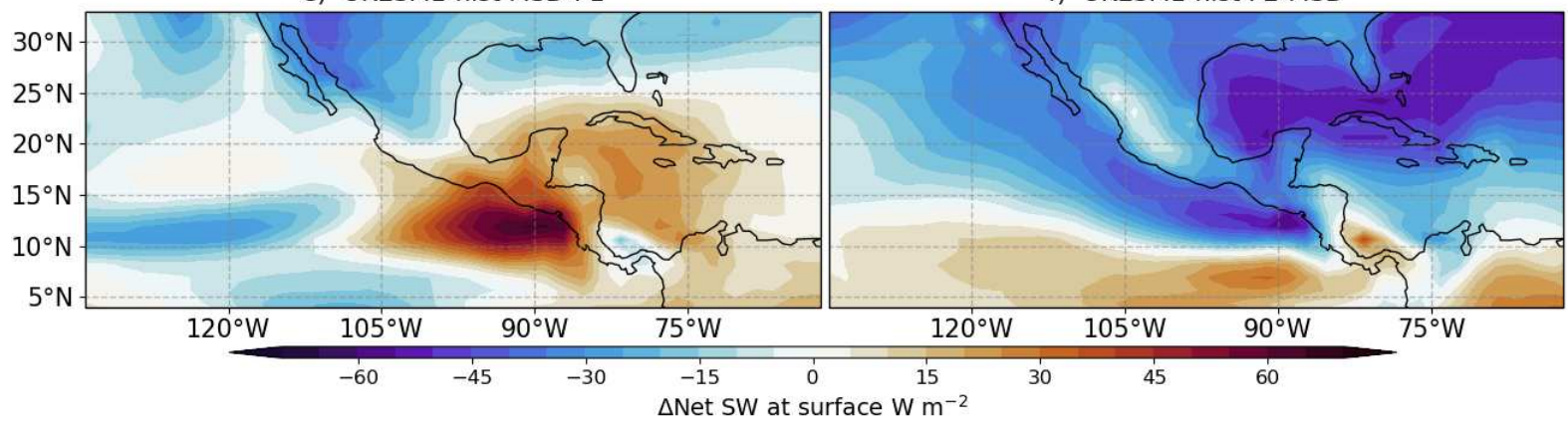

b) ERA-5 P2-MSD

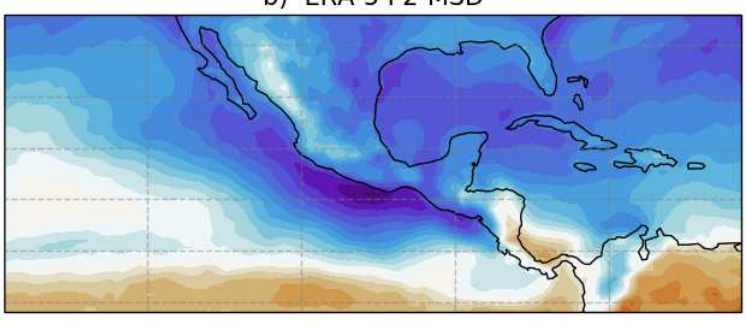

d) GC31-LL hist P2-MSD

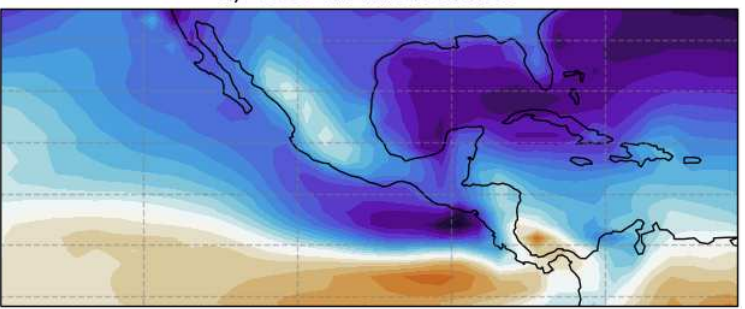

f) UKESM1-hist P2-MSD

Figure 10: As in Fig. 5, but for the net shortwave radiation $\left[\mathrm{W} \mathrm{m}^{-2}\right]$ at the surface. 

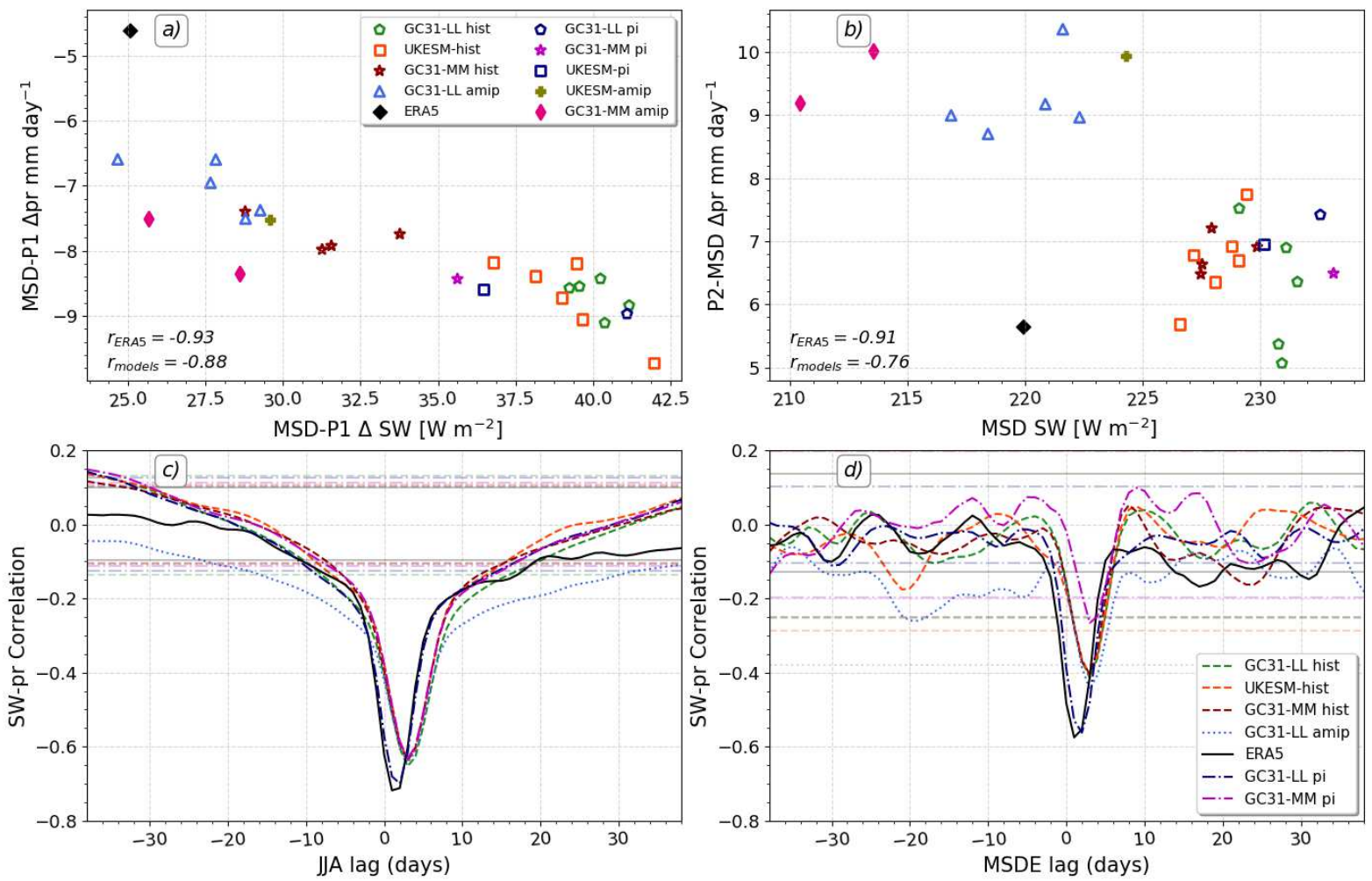

Figure 11: (a, b) Scatter of the mean changes to the net short-wave (SW) at the surface (abscissa) with respect to changes in precipitation, both averaged in the MSD region. (c, d) Lagged-regression coefficients between the net shortwave absorption and precipitation over the MSD region for the (c) the JJA season and (d) around the MSDE date.
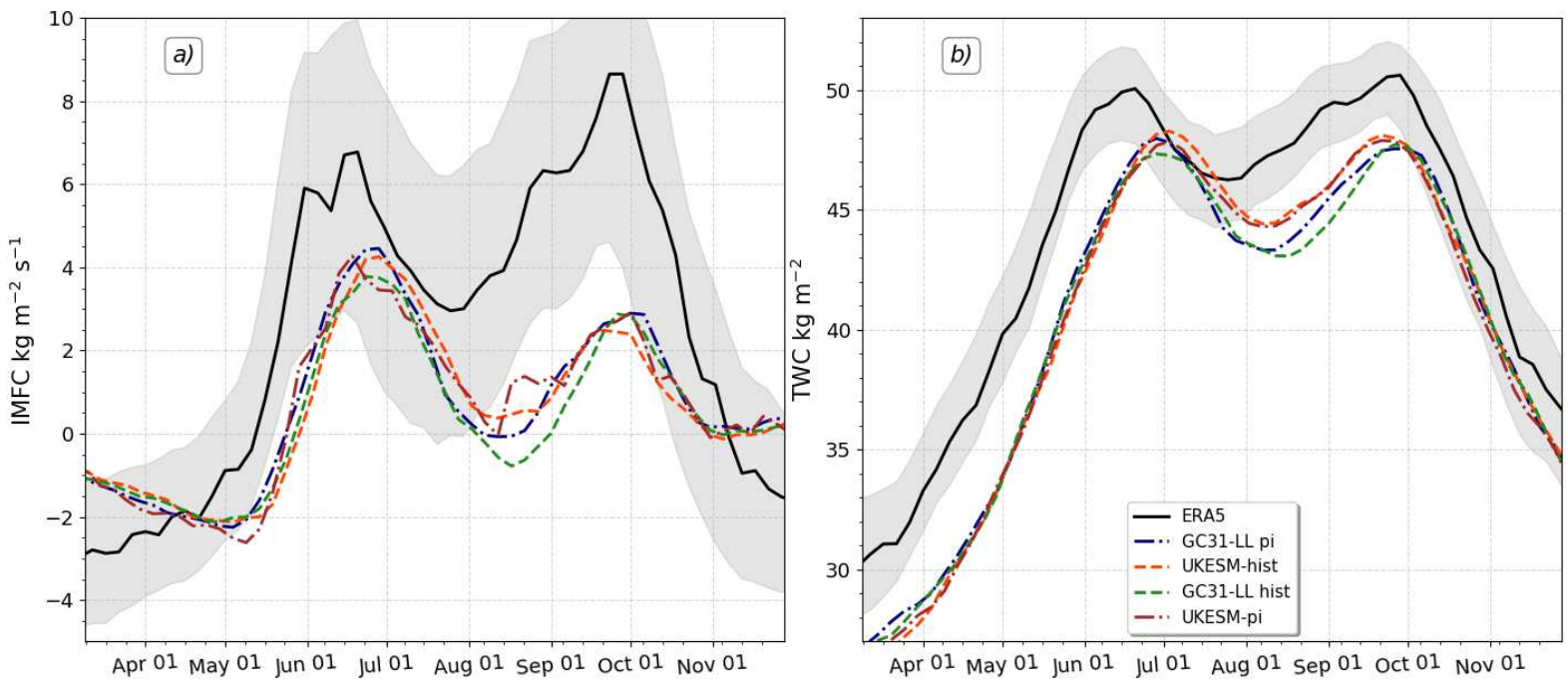

Figure 12: Seasonal cycle of (a) IMFC and (b) TWC averaged over the MSD region for model experiments and ERA5 (see legend). 


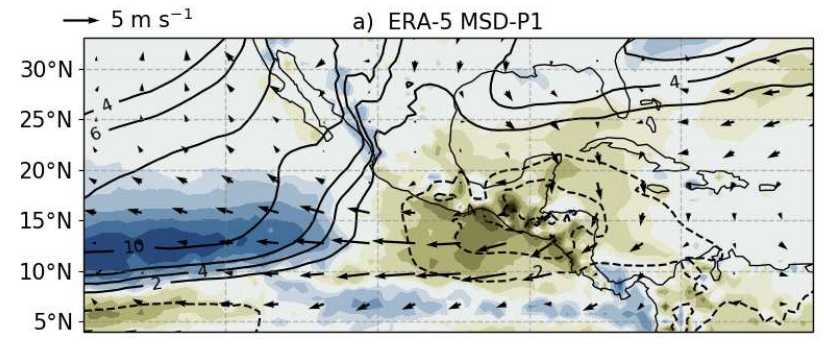

c) GC31-LL hist MSD-P1

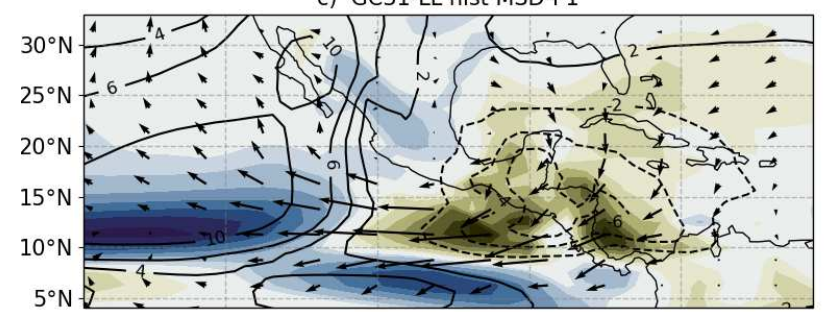

e) UKESM1-hist MSD-P1

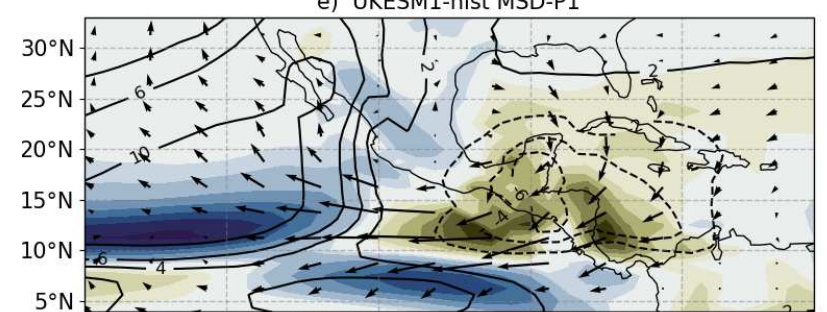

$5^{\circ} \mathrm{N}$

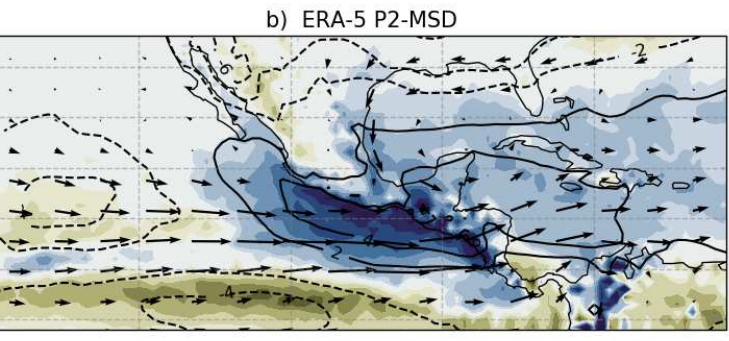

d) GC31-LL hist P2-MSD

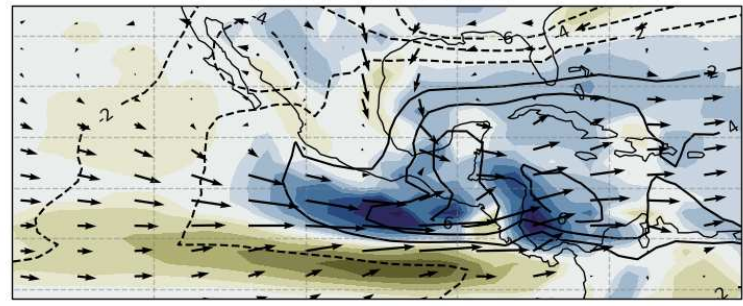

f) UKESM1-hist P2-MSD

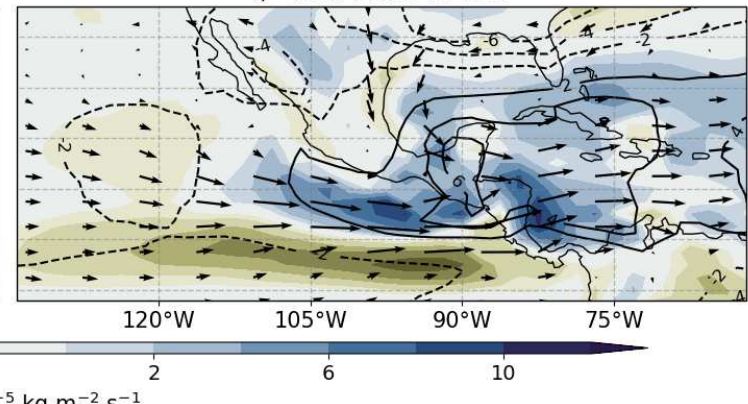

Figure 13: As in Figure 6, but showing variations in the IMFC (shading), TWC (contours in units of kg $\mathrm{m}^{-2}$ ) and $850-\mathrm{hPa}$ wind (vectors; vector size illustrated in the top left corner). 

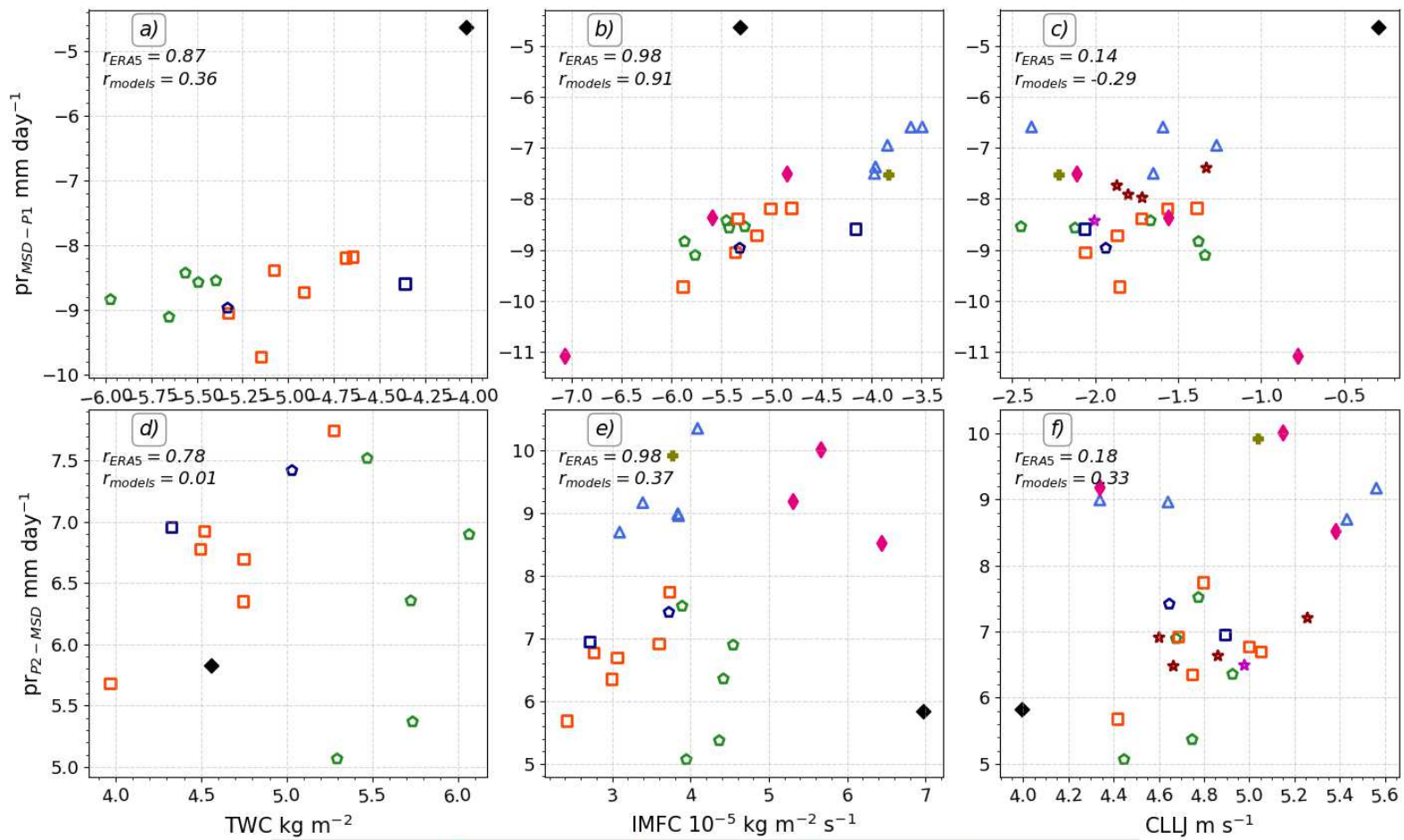

- ERA5 $\square$ UKESM-hist

IMFC $10^{-5} \mathrm{~kg} \mathrm{~m}^{-2} \mathrm{~s}^{-1}$

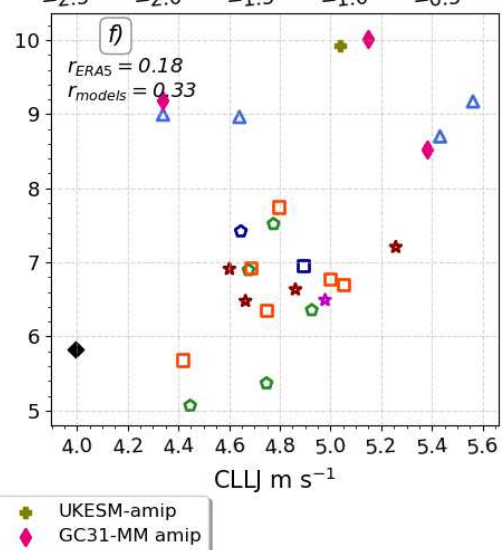

Figure 14: As in Figure 7, showing the scatter of mean changes (a-c) MSD-P1 and (d-f) P2-MSD periods, but using the (a, d) IMFD and (b, e) TWC in the MSD region and the (c, f) CLLJ on the x-axis and precipitation in the MSD region in the y-axis. 

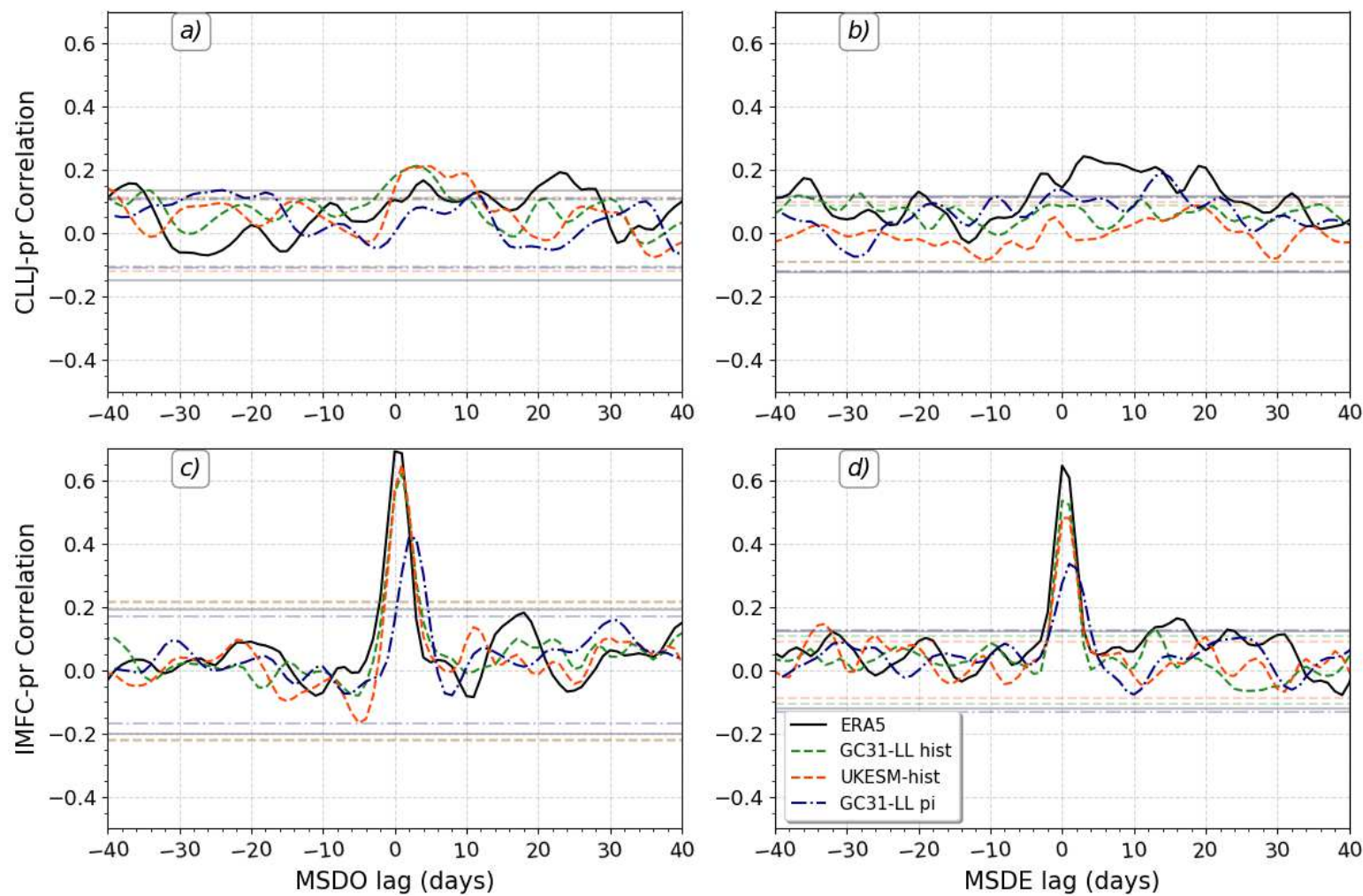

Figure 15: Lagged correlations between precipitation in the MSD region and the (a, b) CLLJ, defined as the $925 \mathrm{hPa}$ zonal wind averaged over the CSEA region, and (c, d) the IMFC over the MSD region. Correlations are shown with lags computed with respect to the (a, c) onset and (b, d) end dates.

a) ERA5-TRMM

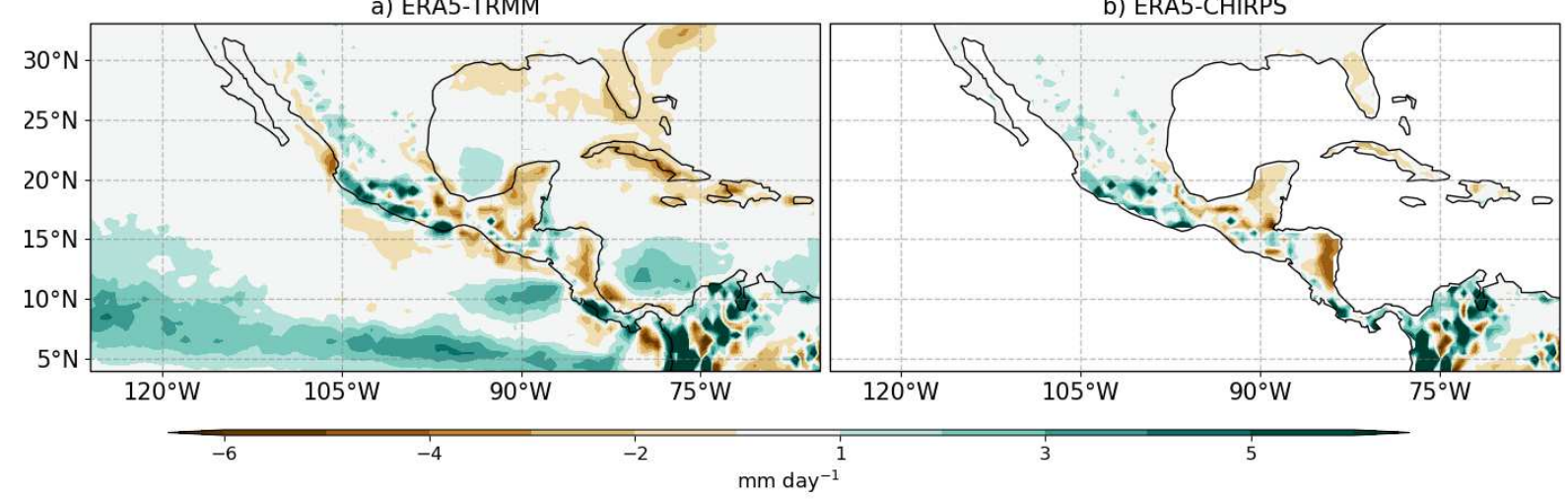

Figure S1: (a, b) JJAS precipitation biases in ERA5 when compared to (a) TRMM and (b) CHIRPS. 
a) JJAS Clim GC31-LL hist-TRMM

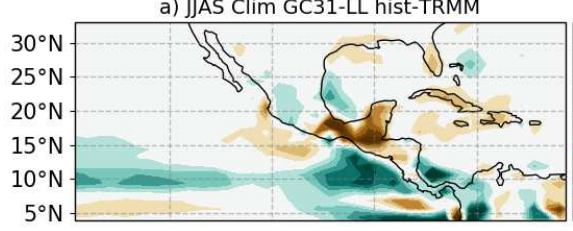

d) JJAS Clim GC31-MM hist-TRMM

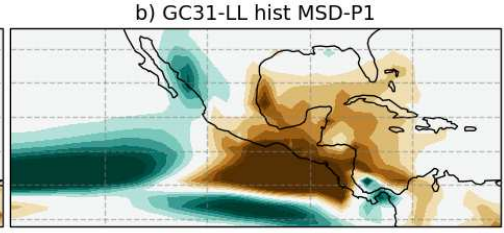

e) GC31-MM hist MSD-P1
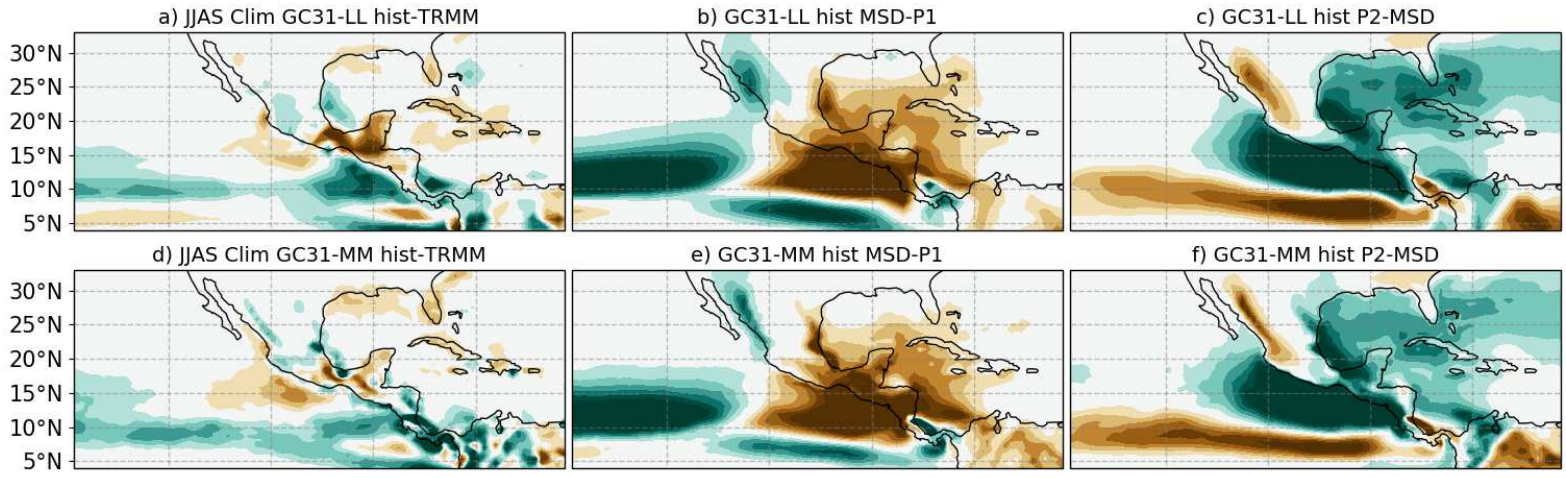

f) GC31-MM hist P2-MSD

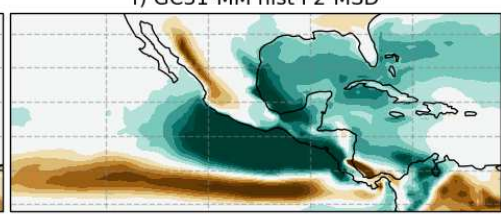

g) JJAS Clim GC31-LL amip-TRMM

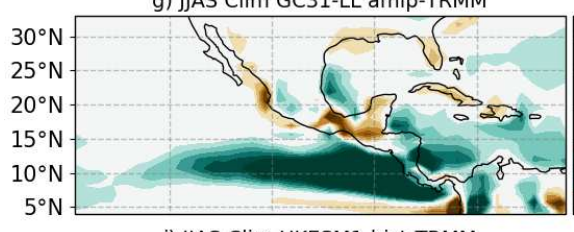

h) GC31-LL amip MSD-P

i) GC31-LL amip P2-MSD
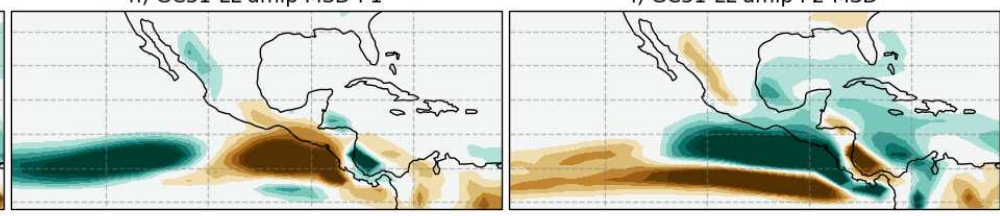

j) JJAS Clim UKESM1-hist-TRMM

k) UKESM1-hist MSD-P1

I) UKESM1-hist P2-MSD

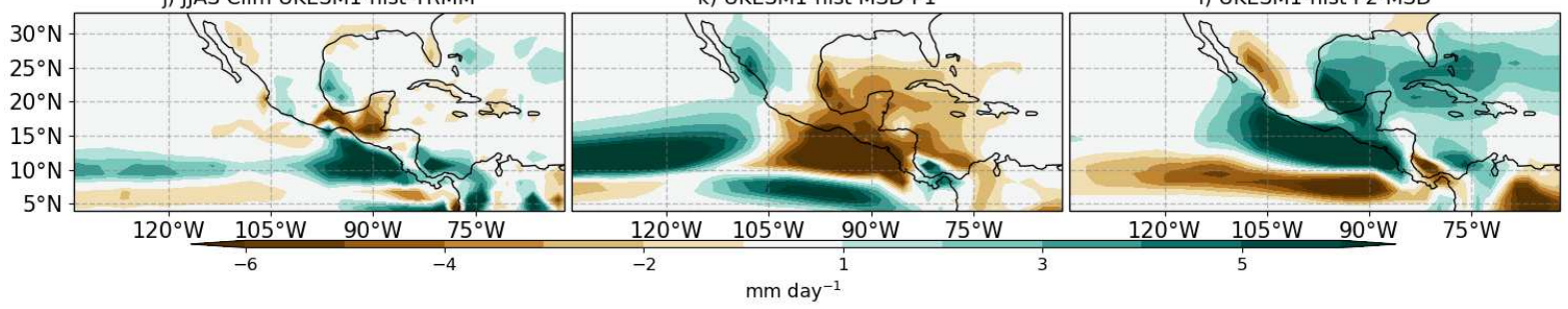

Figure S2: (a, d, g, j) JJAS model bias compared to TRMM and the difference between (b, e, h, k) the midsummer drought and the first peak periods and (c, f, i, l) between the second peak and the midsummer drought periods for four different simulations. 

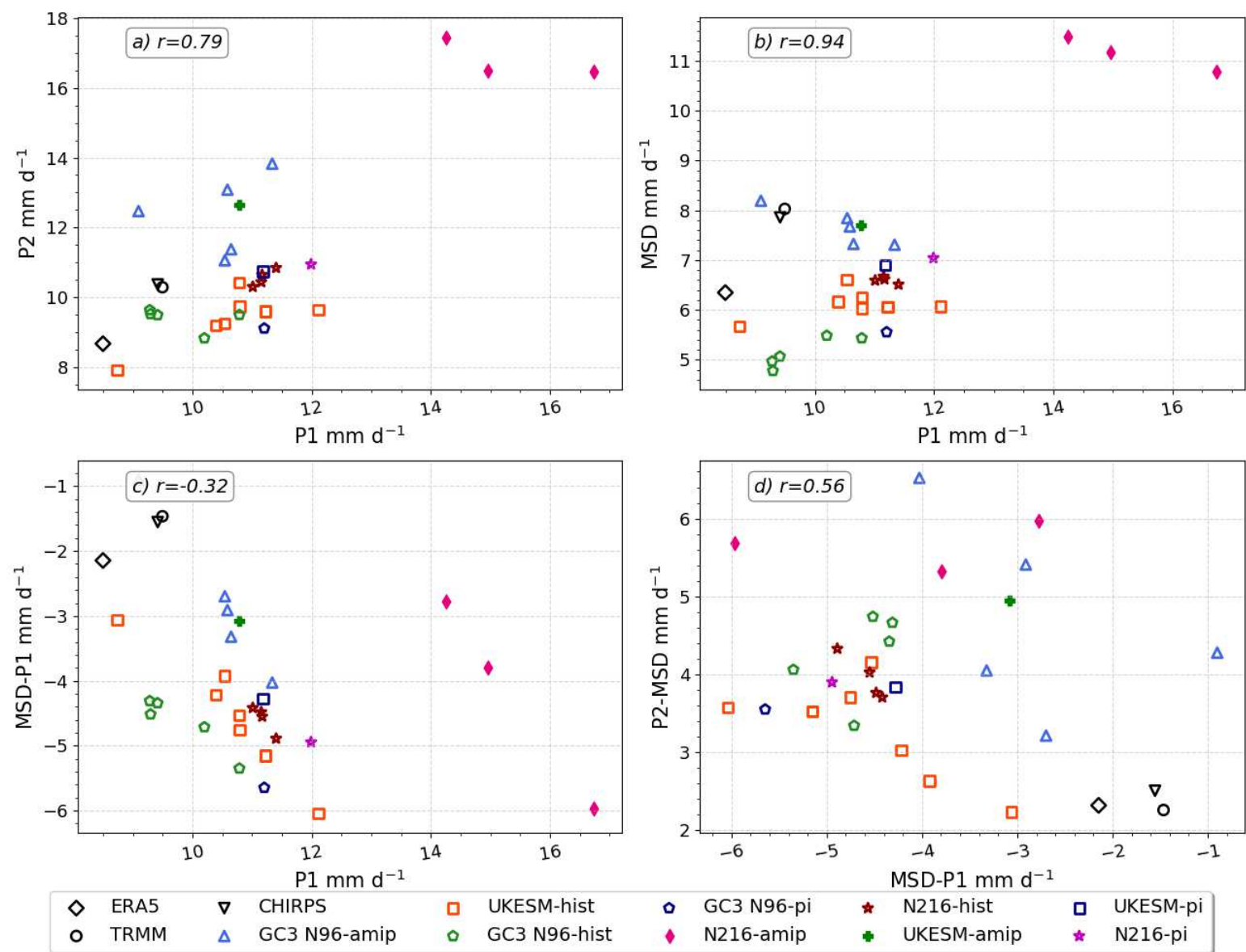

Figure S3: (a, b) Scatter plots of the mean values of precipitation $\left[\mathrm{mm} \mathrm{day}^{-1}\right]$ for TRMM, ERA5, CHIRPS and the CMIP6 experiments (see 2.2) during the first peak (P1), the MSD and the second peak $(\mathrm{P} 2)$ periods and $(\mathrm{c}, \mathrm{d})$ the precipitation differences between the three periods. Precipitation was area-averaged in the region illustrated in Figure 3. Pearson correlation coefficients are shown in the top-left corner of each panel. 

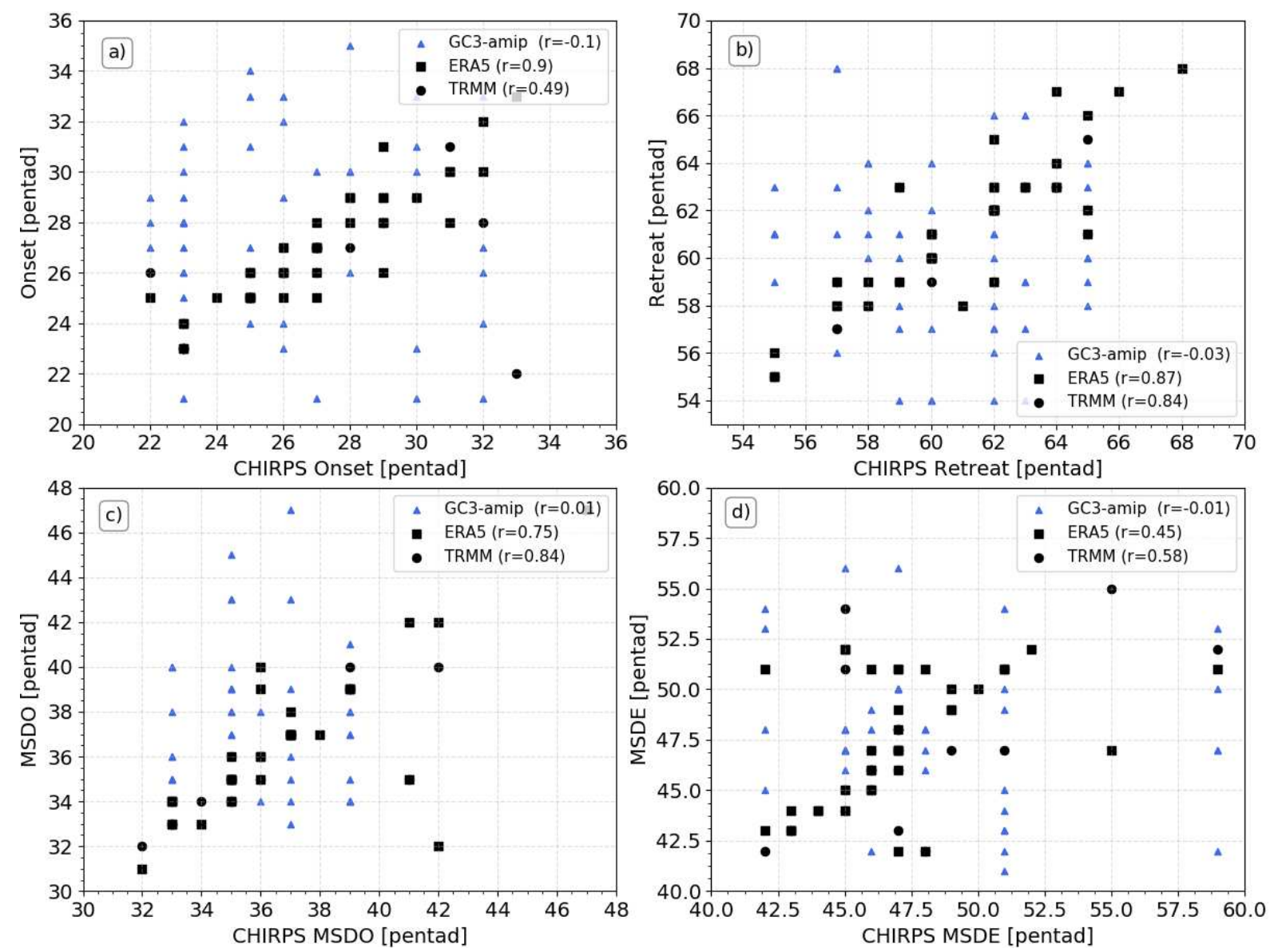

Figure S4: Scatterplots of the pentads diagnosed by the WT method as the dates of (a) monsoon onset (MO), (b) monsoon retreat (MR), (c) MSDO and (d) MSDE where the results of the CHIRPS dataset, on the x-axis, are compared with ERA5, TRMM and the GC31-LL amip simulation, on the y-axis. The legend shows the Pearson $r$ coefficient for each comparison. 
a) ERA-5 P1

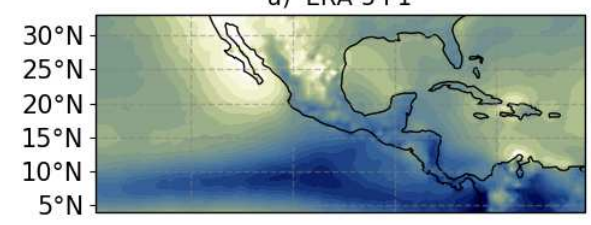

d) GC31-LL hist P1

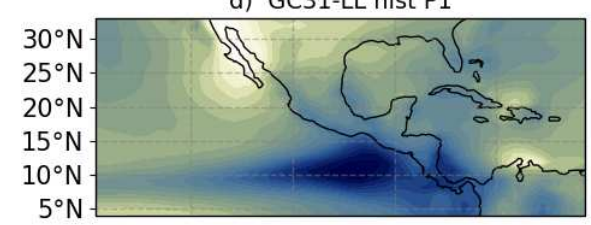

g) GC31-MM hist P1

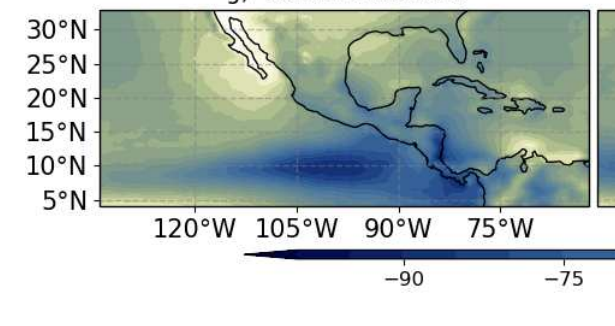

b) ERA-5 MSD

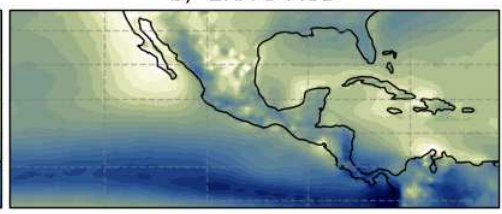

e) GC31-LL hist MSD

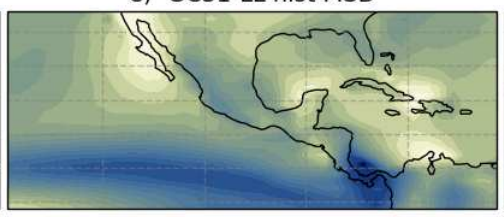

h) GC31-MM hist MSD

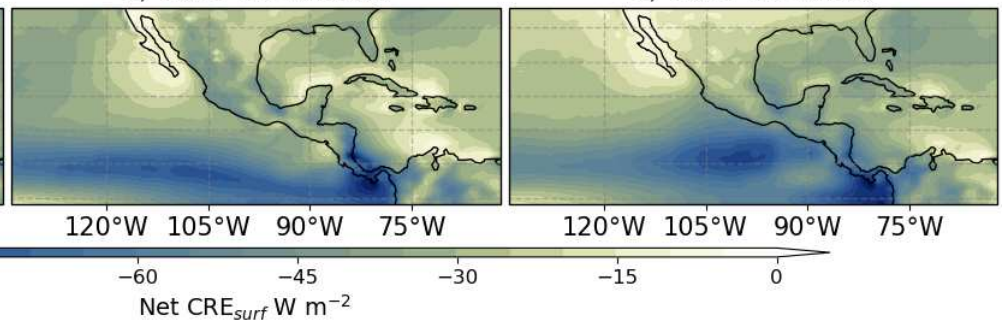

b) ERA-5 P2

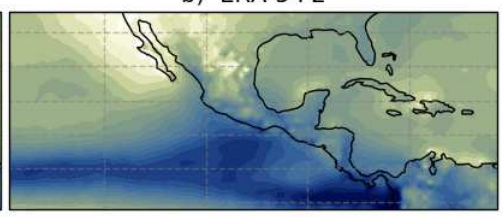

e) GC31-LL hist P2

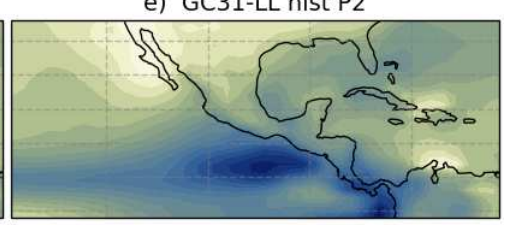

h) GC31-MM hist P2
Figure S5: Composite mean net $\mathrm{CRE}$ at the surface $\left[\mathrm{W} \mathrm{m}^{-2}\right]$ during the periods of onset of the MSD, the MSD and the end of the MSD for (a-c) ERA5, and the ensemble mean of (d-f) GC31-LL hist and (g-h) GC31-MM hist. 
a) ERA-5 MSD-P1

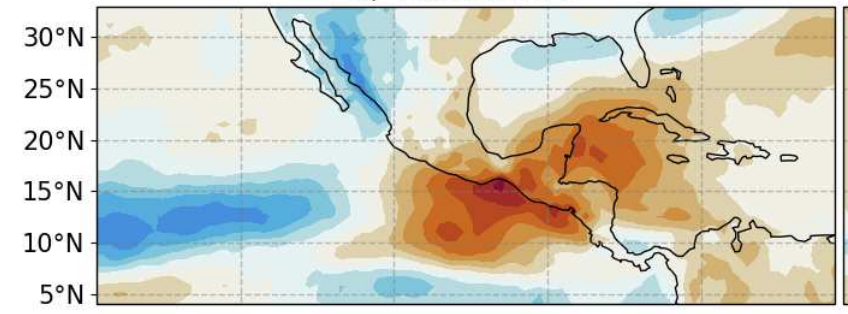

c) GC31-LL hist MSD-P1

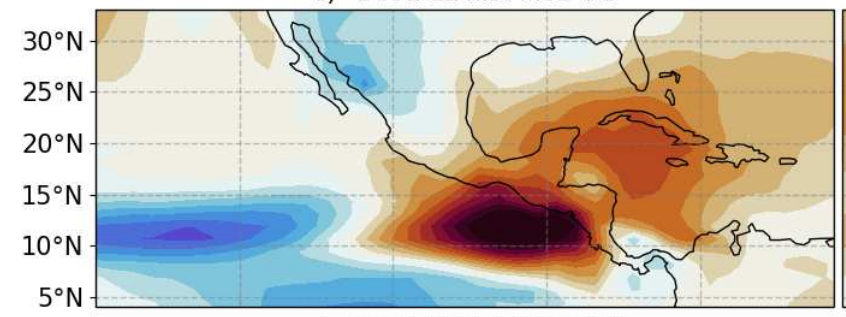

e) GC31-MM hist MSD-P1

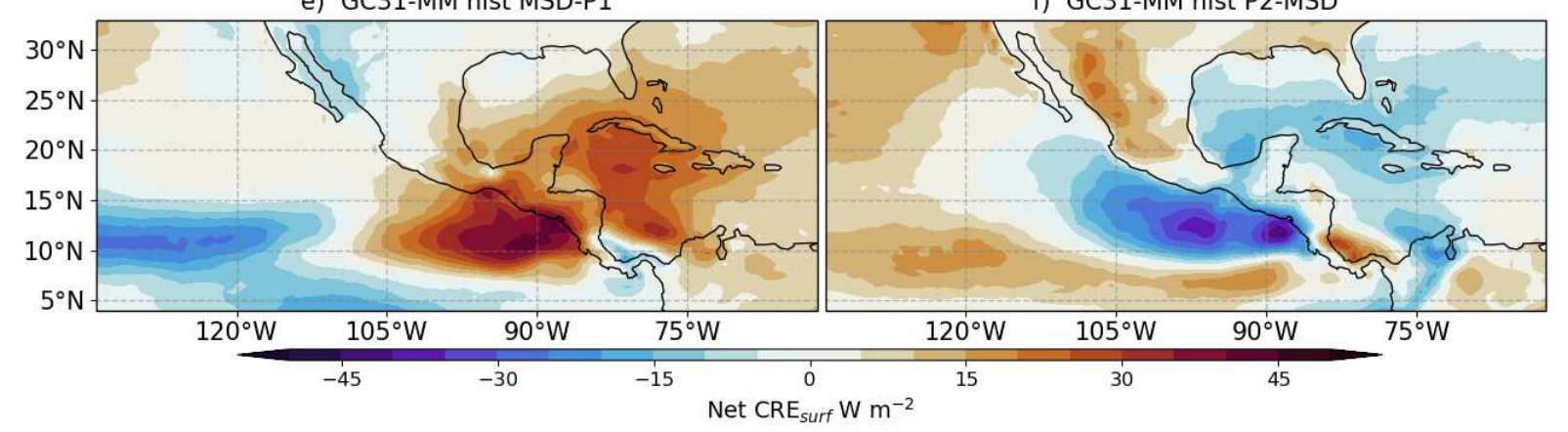

b) ERA-5 P2-MSD

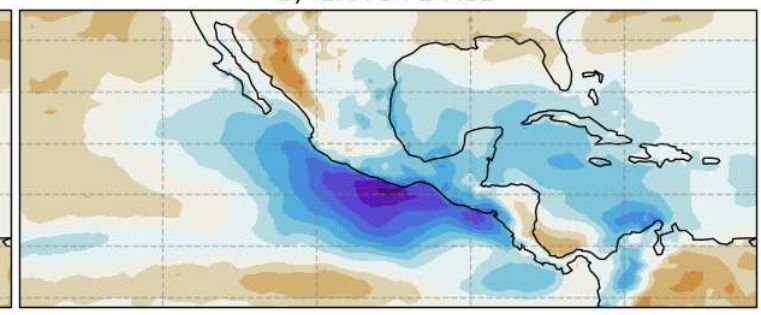

d) GC31-LL hist P2-MSD

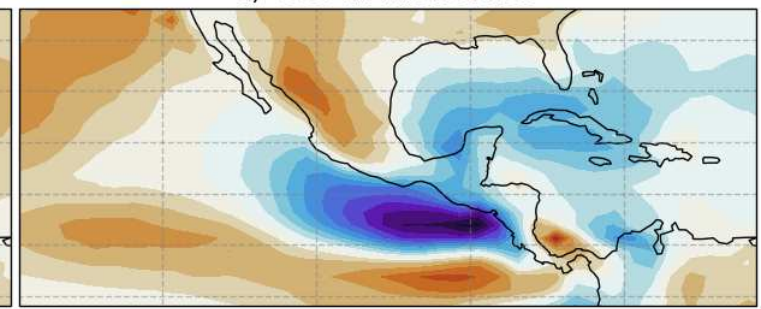

f) GC31-MM hist P2-MSD 


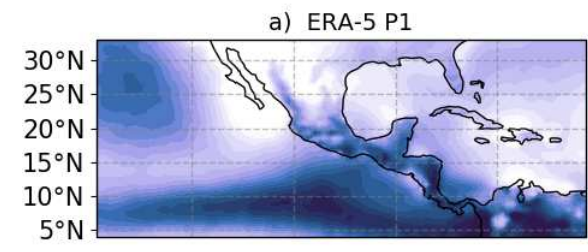

d) GC31-LL hist P1

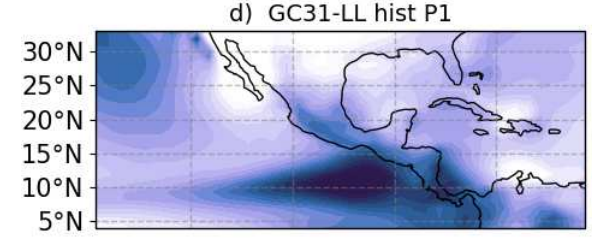

g) GC31-MM hist P1

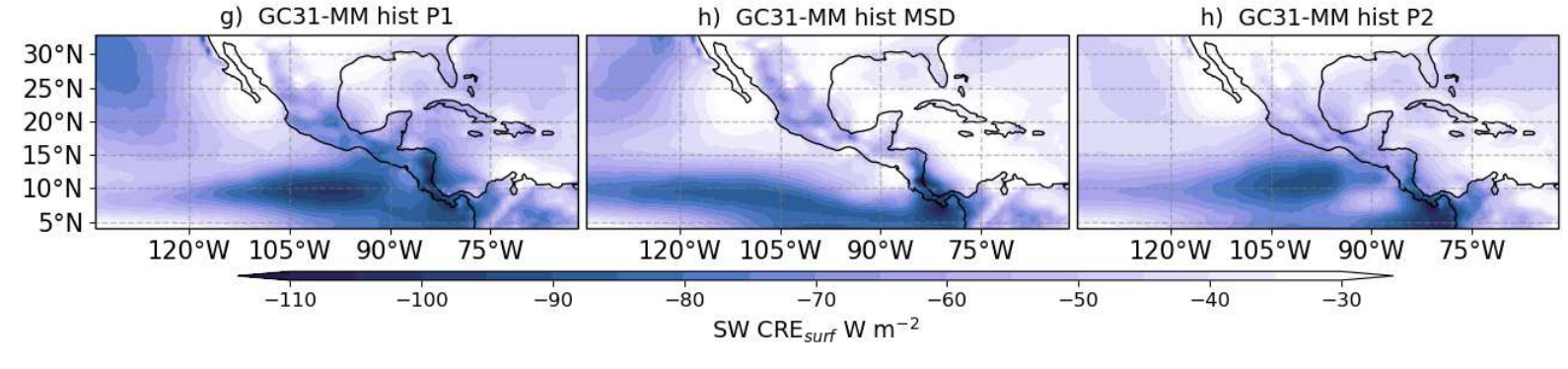

Figure S7: As in Fig. S5 but for the short-wave radiative effect.

b) ERA-5 P2

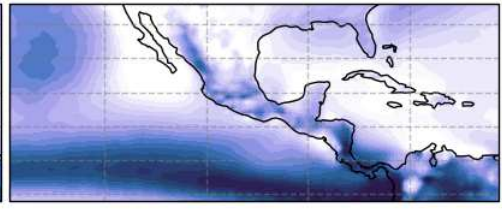

e) GC31-LL hist MSD

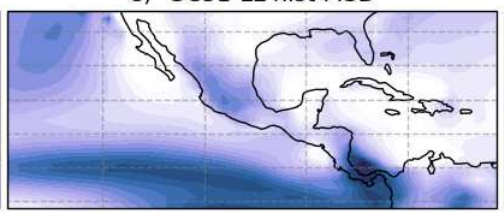

h) GC31-MM hist MSD

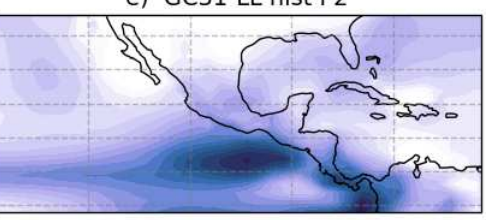

h) GC31-MM hist P2

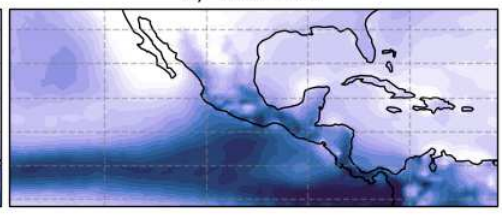

e) GC31-LL hist P2
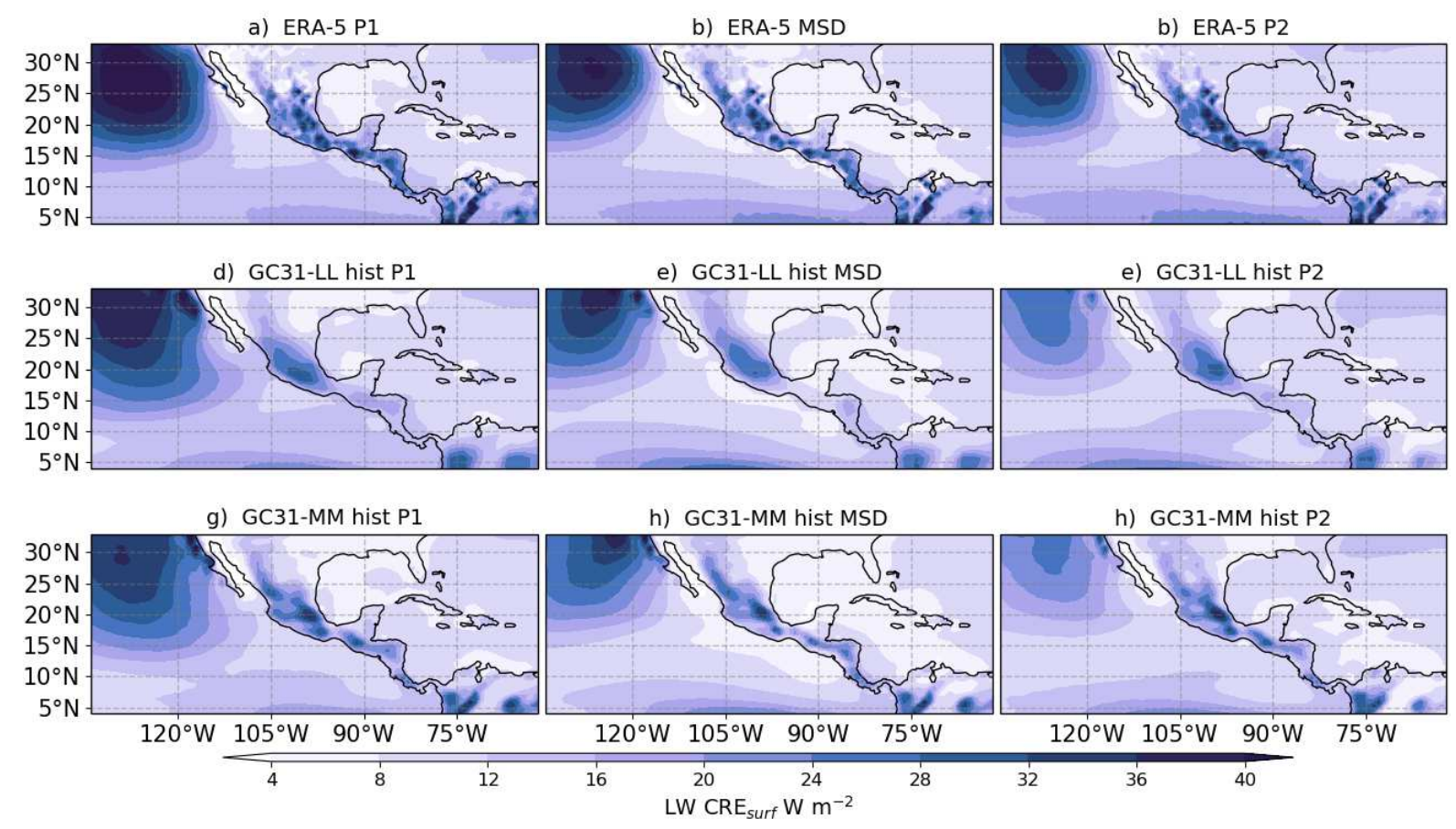

Figure S8: As in Fig. S5 but for the long-wave CRE. 
a) ERA-5 MSD-P1

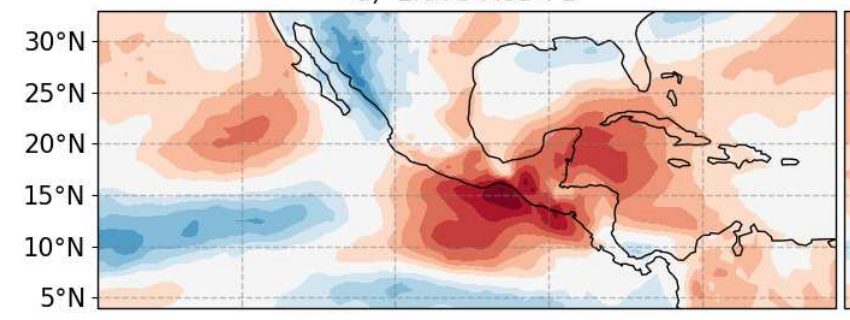

c) GC31-LL hist MSD-P1

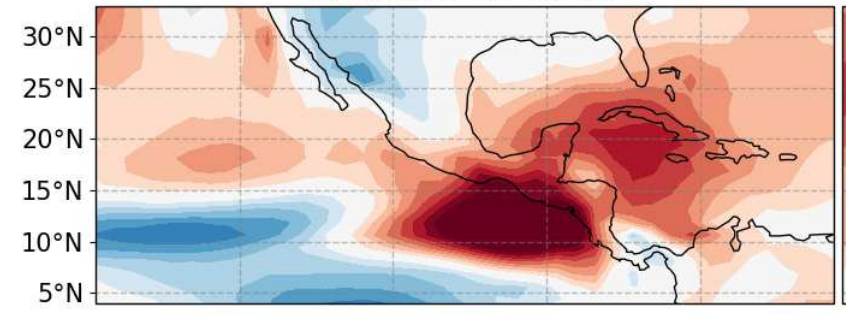

e) GC31-MM hist MSD-P1

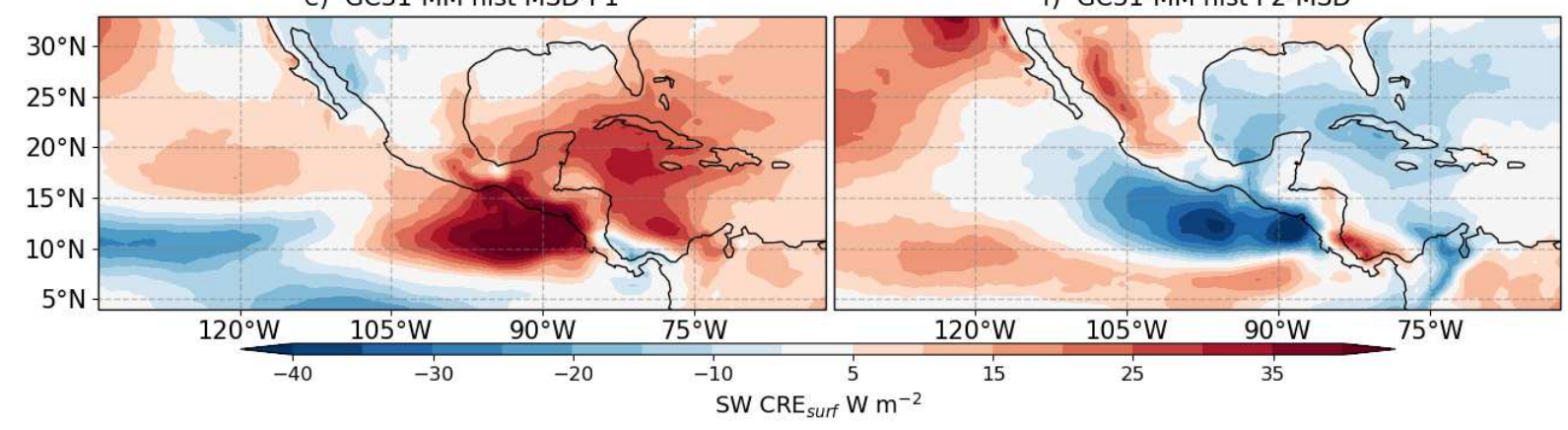

b) ERA-5 P2-MSD

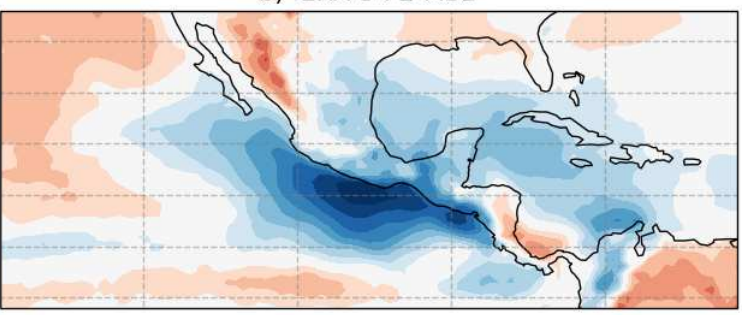

d) GC31-LL hist P2-MSD

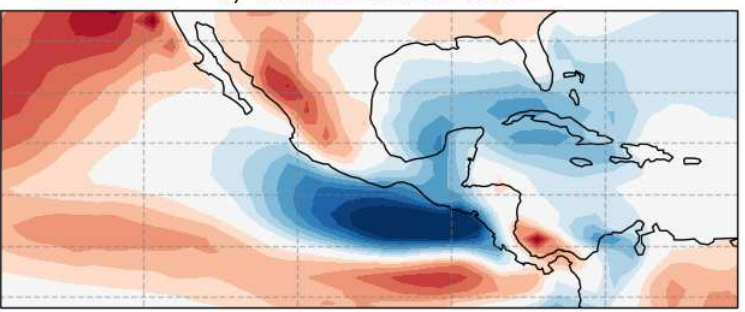

f) GC31-MM hist P2-MSD

Figure S9: Composite mean differences of the SW CRE at the surface $\left[\mathrm{W} \mathrm{m}^{-2}\right]$ for (a-b) ERA5, and the ensemble mean of (c-d) GC31-LL hist and (e-f) GC31-MM hist. 